\title{
Prevention and treatment of low back pain
}

Citation for published version (APA):

Foster, N. E., Anema, J. R., Cherkin, D., Chou, R., Cohen, S. P., Gross, D. P., Ferreira, P. H., Fritz, J. M., Koes, B. W., Peul, W., Turner, J. A., Maher, C. G., Lancet Low Back Pain Series Workin, \& Smeets, R. (2018). Prevention and treatment of low back pain: evidence, challenges, and promising directions.

Lancet, 391(10137), 2368-2383. https://doi.org/10.1016/S0140-6736(18)30489-6

Document status and date:

Published: 09/06/2018

DOI:

10.1016/S0140-6736(18)30489-6

Document Version:

Publisher's PDF, also known as Version of record

Document license:

Taverne

Please check the document version of this publication:

- A submitted manuscript is the version of the article upon submission and before peer-review. There can be important differences between the submitted version and the official published version of record.

People interested in the research are advised to contact the author for the final version of the publication, or visit the DOI to the publisher's website.

- The final author version and the galley proof are versions of the publication after peer review.

- The final published version features the final layout of the paper including the volume, issue and page numbers.

Link to publication

\footnotetext{
General rights rights.

- You may freely distribute the URL identifying the publication in the public portal. please follow below link for the End User Agreement:

www.umlib.nl/taverne-license

Take down policy

If you believe that this document breaches copyright please contact us at:

repository@maastrichtuniversity.nl

providing details and we will investigate your claim.
}

Copyright and moral rights for the publications made accessible in the public portal are retained by the authors and/or other copyright owners and it is a condition of accessing publications that users recognise and abide by the legal requirements associated with these

- Users may download and print one copy of any publication from the public portal for the purpose of private study or research.

- You may not further distribute the material or use it for any profit-making activity or commercial gain

If the publication is distributed under the terms of Article $25 \mathrm{fa}$ of the Dutch Copyright Act, indicated by the "Taverne" license above, 


\title{
Prevention and treatment of low back pain: evidence, challenges, and promising directions
}

\author{
Nadine E Foster, Johannes R Anema, Dan Cherkin, Roger Chou, Steven P Cohen, Douglas P Gross, Paulo H Ferreira, Julie M Fritz, Bart W Koes, \\ Wilco Peul, Judith A Turner, Chris G Maher, on behalf of the Lancet Low Back Pain Series Working Group*
}

Lancet 2018; 391: 2368-83

Published Online

March 21, 2018

http://dx.doi.org/10.1016/

S0140-6736(18)30489-6

See Comment page 2302

See Viewpoint page 2384

This is the second in a Series of

two papers about low back pain

*Members listed at the end of

the report

Arthritis Research UK Primary Care Centre, Research Institute for Primary Care and Health Sciences, Keele University, Staffordshire, UK

(Prof N E Foster DPhil); Department of Public and Occupational Health and Amsterdam Public Health Research Institute, vu University Medical Centre, Amsterdam, Netherlands (ProfJ R Anema PhD); Kaiser Permanente Washington Health Research Institute, Seattle, WA, USA

(D Cherkin PhD); Department of Clinical Epidemiology and

Medical Informatics and

Department of Medicine,

Oregon Health \& Science

University, Portland, OR, USA

(Prof R Chou PhD); Johns Hopkins School of Medicine,

Baltimore, MD, USA

(Prof S P Cohen MD); Walter Reed National Military Medical Center, Bethesda, MD, USA (Prof S P Cohen); Department of Physical Therapy, University of Alberta, Edmonton, AB, Canada (Prof D P Gross PhD); Faculty of Health Sciences, University of Sydney, Sydney, NSW, Australia

(P H Ferreira, PhD); Department of Physical Therapy and Athletic Training, University of Utah, Salt Lake City, UT, USA (Prof) M Fritz PhD); Department of General Practice, Erasmus University Medical Center, Rotterdam, Netherlands (Prof B W Koes PhD);

Department of Neurosurgery, Leiden University, Leiden,

Many clinical practice guidelines recommend similar approaches for the assessment and management of low back pain. Recommendations include use of a biopsychosocial framework to guide management with initial nonpharmacological treatment, including education that supports self-management and resumption of normal activities and exercise, and psychological programmes for those with persistent symptoms. Guidelines recommend prudent use of medication, imaging, and surgery. The recommendations are based on trials almost exclusively from highincome countries, focused mainly on treatments rather than on prevention, with limited data for cost-effectiveness. However, globally, gaps between evidence and practice exist, with limited use of recommended first-line treatments and inappropriately high use of imaging, rest, opioids, spinal injections, and surgery. Doing more of the same will not reduce back-related disability or its long-term consequences. The advances with the greatest potential are arguably those that align practice with the evidence, reduce the focus on spinal abnormalities, and ensure promotion of activity and function, including work participation. We have identified effective, promising, or emerging solutions that could offer new directions, but that need greater attention and further research to determine if they are appropriate for large-scale implementation. These potential solutions include focused strategies to implement best practice, the redesign of clinical pathways, integrated health and occupational interventions to reduce work disability, changes in compensation and disability claims policies, and public health and prevention strategies.

\section{Introduction}

Despite the plethora of treatments and health-care resources devoted to low back pain, back-related disability and population burden have increased. ${ }^{1,2}$ The first paper ${ }^{3}$ in this Series describes the global burden and effect of low back pain and provides an overview of the causes and course of low back pain. In this Series paper, we summarise the evidence for effectiveness of interventions for the prevention and treatment of low back pain and the recommendations from best practice guidelines. Despite generally consistent guideline recommendations around the world, clear evidence exists of substantial gaps between evidence and practice that are pervasive in lowincome, middle-income, and high-income countries. Different response strategies are needed that prevent and minimise disability and promote participation in physical

Search strategy and selection criteria

We identified publications using broad search terms in PubMed and Scopus and based our examples on systematic searches of the published literature. To identify examples from low-income and middle-income countries, we additionally drew on experts in the team either based, or doing research, in these countries. The strength of evidence for the examples of the different solutions to the prevention and management of low back pain varied widely and, therefore, we have incorporated summaries of the extent of evidence and recommendations to strengthen the evidence base to inform future international efforts. and social activities. Here we highlight examples of effective, promising, or emerging solutions from around the world and make recommendations to strengthen the evidence base for them.

\section{Prevention}

By contrast with the large number of trials that assess treatments for low back pain, evidence about prevention, particularly primary prevention, is inadequate (table 1). Most of the widely promoted interventions to prevent low back pain (eg, work-place education, no-lift policies, ergonomic furniture, mattresses, back belts, lifting devices) do not have a firm evidence base. A 2016 systematic review ${ }^{4}$ identified only 21 trials with 30850 adults (one in a low-middle-income country [Thailand]), and a 2014 systematic review ${ }^{5}$ analysed only 11 randomised controlled trials with 2700 children (one in a low-middleincome country [Brazil]). The authors of the review in adults concluded that moderate quality evidence existed that exercise alone, or in combination with education, is effective for prevention; and poor to very-poor quality evidence existed that education alone, back belts, shoe insoles, and ergonomic programmes might not be effective. ${ }^{4}$ The preventive effect of exercise and education was large, with a pooled relative risk of 0.55 (95\% CI $0.41-0.74)$; however, the trials were mainly of secondary prevention and the effective programmes were quite intensive (eg, 20 1-hour sessions of supervised exercise in one trial). ${ }^{4}$ The authors of the review in children concluded that moderate quality evidence existed that education is not effective and very low quality evidence existed that 
ergonomically designed furniture could prevent low back pain compared with conventional furniture. ${ }^{5}$

\section{Treatment}

Low back pain without a known cause is referred to as non-specific low back pain and guidelines ${ }^{5-8}$ recommend use of a biopsychosocial model to inform assessment and management in view of associations between behavioural, psychological, and social factors and the future persistence of pain and disability. Guidelines also recommend that laboratory tests and imaging should not be routinely used as part of early management, but rather reserved for patients for whom the result is likely to change management (eg, if a serious condition, such as infection, is suspected).

During the past three decades, changes have been made to key recommendations in national clinical practice guidelines. Greater emphasis is now placed on selfmanagement, physical and psychological therapies, and some forms of complementary medicine, and less emphasis on pharmacological and surgical treatments. Guidelines encourage active treatments that address psychosocial factors and focus on improvement in function. The changed understanding of how best to manage low back pain is shown in three current guidelines, from Denmark, ${ }^{6}$ the USA, ${ }^{7}$ and the UK. ${ }^{8}$ The reduced emphasis on pharmacological care is shown by the US guideline, ${ }^{7}$ which recommends nonpharmacological care as the first treatment option and reserves pharmacological care for patients for whom nonpharmacological care has not worked. These guidelines endorse the use of exercise (Danish, US, and UK guidelines) and a range of other non-pharmacological therapies, alone and in combination, such as massage (US and UK), acupuncture (US), spinal manipulation (Danish, US, and UK), Tai Chi (US), and yoga (US).

Table 2 summarises the key recommendations of the three clinical guidelines for the management of low back pain and radicular pain, ${ }^{6-8}$ separated by duration of symptoms when information is available. Consistent recommendations for early management are that individuals should be provided with advice and education about the nature of low back pain and radicular pain; reassurance that they do not have a serious disease and that symptoms will improve over time; and encouragement to avoid bed rest, stay active, and continue with usual activities, including work. ${ }^{8}$ Early supervised exercise therapy is typically unnecessary; ${ }^{9}$ however, it can be considered if recovery is slow or for patients with risk factors for persistent disabling pain. ${ }^{9}$ For acute radiculopathy without severe or progressive motor weakness, data are insufficient to suggest that initial management should differ from that of acute non-specific low back pain. ${ }^{8,9}$

Recommended physical treatments, particularly for persistent low back pain (>12 weeks duration), include a graded activity or exercise programme that targets

\section{Key messages}

- Guidelines recommend self-management, physical and psychological therapies, and some forms of complementary medicine, and place less emphasis on pharmacological and surgical treatments; routine use of imaging and investigations is not recommended

- Little prevention research exists, with the only known effective interventions for secondary prevention being exercise combined with education, and exercise alone

- The evidence for prevention and treatment comes mainly from adults in high-income countries and whether the resulting recommendations are appropriate for children or those in low-income and middle-income countries is not known

- Non-evidence-based practice is apparent across all income settings; common problems are presentations to emergency departments and liberal use of imaging, opioids, spinal injections, and surgery

- Promising solutions include focused implementation of best practice, the redesign of clinical pathways, integrated health and occupational care, changes to payment systems and legislation, and public health and prevention strategies

- The evidence underpinning these solutions is inadequate and whether they are appropriate for widespread implementation is not known

- Further testing of these promising solutions, and development of new solutions, is needed, particularly in low-income and middle-income countries

\begin{tabular}{|lll|}
\hline & Effect in adults $^{4}$ & Effect in children $^{5}$ \\
\hline Exercise and education & Effective (moderate quality) $^{\text {Ex }}$ & No trials available \\
Exercise & Effective (low quality) & No trials available \\
Education & Ineffective (moderate quality) & Ineffective (moderate quality) \\
Back belt & Ineffective (very low quality) & No trials available \\
Shoe insoles & Ineffective (low quality) & No trials available \\
\hline Ergonomic interventions at workplace & Ineffective (moderate quality) & No trials available \\
Ergonomic school furniture & NA & Effective (very low quality)
\end{tabular}

$\mathrm{NA}=$ not applicable.

Table 1: Evidence of prevention strategies for low back pain: conclusions on effectiveness (and GRADE strength of evidence ratings) from systematic reviews

improvements in function and prevention of worsening disability. Since evidence showing that one form of exercise is better than another is not available, guidelines recommend exercise programmes that take individual needs, preferences, and capabilities into account in deciding about the type of exercise. Some guidelines do not recommend passive therapies, such as spinal manipulation or mobilisation, massage, and acupuncture, some consider them optional, and others suggest a short course for patients who do not respond to other treatment. ${ }^{10}$ Other passive electrical or physical modalities, such as ultrasound, transcutaneous electrical nerve stimulation,
Netherlands (Prof W Peul PhD) Department of Psychiatry and Behavioral Sciences, and Department of Rehabilitation Medicine, University of Washington School of Medicine, Seattle, WA, USA (Prof J A Turner PhD); and Sydney School of Public Health, University of Sydney, NSW, Australia (Prof C G Maher PhD)

Correspondence to: Prof Nadine E Foster, Arthritis Research UK Primary Care Centre, Research Institute for Primary Care and Health Sciences, Keele University, Staffordshire ST5 5BG, UK n.foster@keele.ac.uk 


\begin{tabular}{|c|c|c|}
\hline & $\begin{array}{l}\text { Acute low back pain } \\
\text { ( } 66 \text { weeks) }\end{array}$ & $\begin{array}{l}\text { Persistent low back pain } \\
\text { ( }>12 \text { weeks) }\end{array}$ \\
\hline \multicolumn{3}{|l|}{ Education and self-care } \\
\hline Advice to remain active & $\begin{array}{l}\text { First-line treatment, consider for } \\
\text { routine use }\end{array}$ & $\begin{array}{l}\text { First-line treatment, consider for } \\
\text { routine use }\end{array}$ \\
\hline Education & $\begin{array}{l}\text { First-line treatment, consider for } \\
\text { routine use }\end{array}$ & $\begin{array}{l}\text { First-line treatment, consider for } \\
\text { routine use }\end{array}$ \\
\hline Superficial heat & $\begin{array}{l}\text { Second-line or adjunctive } \\
\text { treatment option }\end{array}$ & Insufficient evidence \\
\hline \multicolumn{3}{|l|}{ Non-pharmacological therapy } \\
\hline Exercise therapy & Limited use in selected patients & $\begin{array}{l}\text { First-line treatment, consider for } \\
\text { routine use }\end{array}$ \\
\hline Cognitive behavioural therapy & Limited use in selected patients & $\begin{array}{l}\text { First-line treatment, consider for } \\
\text { routine use }\end{array}$ \\
\hline Spinal manipulation & $\begin{array}{l}\text { Second-line or adjunctive } \\
\text { treatment option }\end{array}$ & $\begin{array}{l}\text { Second-line or adjunctive } \\
\text { treatment option }\end{array}$ \\
\hline Massage & $\begin{array}{l}\text { Second-line or adjunctive } \\
\text { treatment option }\end{array}$ & $\begin{array}{l}\text { Second-line or adjunctive } \\
\text { treatment option }\end{array}$ \\
\hline Acupuncture & $\begin{array}{l}\text { Second-line or adjunctive } \\
\text { treatment option }\end{array}$ & $\begin{array}{l}\text { Second-line or adjunctive } \\
\text { treatment option }\end{array}$ \\
\hline Yoga & Insufficient evidence & $\begin{array}{l}\text { Second-line or adjunctive } \\
\text { treatment option }\end{array}$ \\
\hline $\begin{array}{l}\text { Mindfulness-based stress } \\
\text { reduction }\end{array}$ & Insufficient evidence & $\begin{array}{l}\text { Second-line or adjunctive } \\
\text { treatment option }\end{array}$ \\
\hline Interdisciplinary rehabilitation & Insufficient evidence & $\begin{array}{l}\text { Second-line or adjunctive } \\
\text { treatment option }\end{array}$ \\
\hline \multicolumn{3}{|l|}{ Pharmacological therapy } \\
\hline Paracetamol & Not recommended & Not recommended \\
\hline $\begin{array}{l}\text { Non-steroidal anti-inflammatory } \\
\text { drugs }\end{array}$ & $\begin{array}{l}\text { Second-line or adjunctive } \\
\text { treatment option }\end{array}$ & $\begin{array}{l}\text { Second-line or adjunctive } \\
\text { treatment option }\end{array}$ \\
\hline Skeletal muscle relaxants & Limited use in selected patients & Insufficient evidence \\
\hline $\begin{array}{l}\text { Selective norepinephrine reuptake } \\
\text { inhibitors }\end{array}$ & Insufficient evidence & $\begin{array}{l}\text { Second-line or adjunctive } \\
\text { treatment option }\end{array}$ \\
\hline Antiseizure medications & Insufficient evidence & Role uncertain \\
\hline Opioids & $\begin{array}{l}\text { Limited use in selected patients, } \\
\text { use with caution }\end{array}$ & $\begin{array}{l}\text { Limited use in selected patients, use } \\
\text { with caution }\end{array}$ \\
\hline Systemic glucocorticoids & Not recommended & Not recommended \\
\hline \multicolumn{3}{|l|}{ Interventional therapies } \\
\hline $\begin{array}{l}\text { Epidural glucocorticoid injection } \\
\text { (for herniated disc with } \\
\text { radiculopathy) }\end{array}$ & Not recommended & Limited use in selected patients \\
\hline \multicolumn{3}{|l|}{ Surgery } \\
\hline $\begin{array}{l}\text { Discectomy (for herniated disc } \\
\text { with radiculopathy) }\end{array}$ & Insufficient evidence & $\begin{array}{l}\text { Second-line or adjunctive } \\
\text { treatment option }\end{array}$ \\
\hline $\begin{array}{l}\text { Laminectomy (for symptomatic } \\
\text { spinal stenosis) }\end{array}$ & Insufficient evidence & $\begin{array}{l}\text { Second-line or adjunctive } \\
\text { treatment option }\end{array}$ \\
\hline $\begin{array}{l}\text { Spinal fusion (for non-radicular } \\
\text { low back pain with degenerative } \\
\text { disc findings) }\end{array}$ & Insufficient evidence & Role uncertain \\
\hline
\end{tabular}

Subacute low back pain is a transition period between acute and chronic low back pain; evidence on optimal therapies for subacute low back pain is scarce but a reasonable approach is to shift towards therapies recommended for chronic low back pain.

Table 2: Overview of interventions endorsed for non-specific low back pain in evidence-based clinical practice guidelines (Danish, ${ }^{6} \mathrm{US}^{7}{ }^{7}$ and $\mathrm{UK}^{8}$ guidelines)

traction, interferential therapy, short-wave diathermy, and back supports are generally ineffective and not recommended..$^{6-8}$

Guidelines also recommend consideration of psychological therapies-eg, cognitive behavioural therapy, progressive relaxation, and mindfulness-based stress reduction-and combined packages of physical and psychological treatment, for those with persistent low back pain or radicular pain who have not responded to previous treatments. ${ }^{6-8}$ For patients who have not responded to firstline treatments, and who are substantially functionally disabled by pain, multidisciplinary rehabilitation programmes with coordinated delivery of supervised exercise therapy, cognitive behavioural therapy, and medication are more effective than standard treatments. ${ }^{6-8,11}$

Guidelines now recommend pharmacological treatment only following an inadequate response to first-line nonpharmacological interventions. Paracetamol was once the recommended first-line medicine for low back pain; however, evidence ${ }^{12}$ of absence of effectiveness in acute low back pain and potential for harm has led to recommendations against its use. ${ }^{7.8}$ Health professionals are guided to consider oral non-steroidal anti-inflammatory drugs (NSAIDs), taking into account risks, including gastrointestinal, liver, and cardiorenal toxicity, and if using, to prescribe the lowest effective dose for the shortest possible time. ${ }^{8}$ Routine use of opioids is not recommended, since benefits are small and substantial risks exist, including overdose and addiction potential, and poorer long-term outcomes than without use., ${ }^{9,13}$ Guidelines caution that opioid therapy should be used only in carefully selected patients, for a short duration, ${ }^{13}$ and with appropriate monitoring. The role of gabaergic drugs, such as pregabalin, is now being reconsidered after a 2017 trial showed pregabalin to be ineffective for radicular pain. ${ }^{14}$ Guidelines generally suggest consideration of muscle relaxants for short-term use, although further research is recommended. ${ }^{8}$

The role of interventional therapies and surgery is limited and recommendations in clinical guidelines vary. Recent guidelines ${ }^{6-8}$ do not recommend spinal epidural injections or facet joint injections for low back pain but do recommend consideration of epidural injections of local anaesthetic and steroid for severe radicular pain. ${ }^{8}$ Epidural injections are associated with small short-term $(<4$ weeks) reductions in pain, do not seem to provide long-term benefits or reduce the longterm risk of surgery, ${ }^{6,15}$ and have been associated with rare but serious adverse events, including loss of vision, stroke, paralysis, and death. ${ }^{16}$ The UK guideline ${ }^{8}$ suggests consideration of radiofrequency denervation for chronic low back pain that is unresponsive to non-surgical treatments; however, the subsequently published MINT $\operatorname{trial}^{17}$ challenge this recommendation.

The benefits of spinal fusion surgery for non-radicular low back pain thought to originate from degenerated lumbar discs (known as discogenic) are similar to those of intensive multidisciplinary rehabilitation and only modestly greater than standard non-surgical management. ${ }^{18}$ Surgery is also more costly and carries a greater risk of adverse events than non-surgical management. The UK guidelines recommend that patients are not 
offered disc replacement or spinal fusion surgery for low back pain, and instead recommend offering fusion surgery only as part of a randomised trial. ${ }^{8}$ Patients with severe or progressive neurological deficits require surgical referral. ${ }^{19}$ Spinal decompression surgery can be considered for radicular pain when non-surgical treatments have been unsuccessful and clinical and imaging findings indicate association of symptoms with herniated discs or spinal stenosis. ${ }^{8}$ For a herniated disc, early surgery is associated with faster relief of radiculopathy than with initial conservative treatment with the option of delayed surgery, but benefits diminish with longer ( $>1$ year) follow-up. ${ }^{19}$ For symptoms associated with lumbar spinal stenosis, benefits of surgery over conservative care are not clear but some beneficial effects have been shown. ${ }^{20}$ However, patients tend to improve with or without surgery and, therefore, non-surgical management is an appropriate option for patients who wish to defer or avoid surgery. ${ }^{20}$

The evidence underpinning low back pain guidelines is drawn almost exclusively from clinical trials of adults. A 2014 systematic review found only four paediatric trials, ${ }^{5}$ so great uncertainty exists about the treatment of back pain in children. The trial evidence is also mainly from high-income countries and, therefore, whether these guideline recommendations are appropriate for low-income and middle-income countries is not known. Guidelines developed in low-income and middleincome countries (eg, Philippines, ${ }^{21}$ Brazil $^{22}$ ) provide near identical recommendations to those in highincome countries. Factors such as cultural acceptability of treatments, patient attitudes towards and adherence to treatment, and treatment providers could vary systematically between countries and influence treatment outcomes. Furthermore, in some countries access to some treatments endorsed in guidelines is poor or non-existent.

\section{The global gap between evidence and practice}

Despite multiple clinical guidelines providing similar recommendations for managing low back pain, a substantial gap between evidence and practice exists worldwide in high-income as well as low-income and middle-income countries. ${ }^{23}$ Problems include both overuse of low-value care and underuse of high-value care. Panel 1 shows studies of clinical practice and highlights the disparity between ten guideline recommendations and the reality of current health care. Tremendous opportunity exists to improve health-care outcomes and potentially reduce costs by effectively implementing known best practice recommendations.

In high-income countries, guidelines recommend education and advice to keep active and at work; yet, data from Australia ${ }^{36}$ and Qatar ${ }^{37}$ show that such advice is provided only in a few consultations. By contrast with the guideline message that first-line care should be nonpharmacological, a study from the USA showed that only about half of people with chronic low back pain are prescribed exercise. ${ }^{56}$ In Australian primary care ${ }^{48}$ and in the emergency department setting in Canada, ${ }^{70}$ the most common treatment is prescribed medication. Although physical therapists are in an excellent position to provide exercise advice, surveys from Sweden, ${ }^{49}$ the USA, ${ }^{50}$ and Australia ${ }^{51}$ show high rates of use of electrical modalities, which the evidence shows are ineffective.

Despite the guideline message that low back pain should be managed in primary care, since few cases constitute medical emergencies, studies from France, ${ }^{24}$ Australia, ${ }^{26}$ Italy, ${ }^{41}$ and the USA ${ }^{71}$ show that patients often present to the emergency department. Although imaging has a very limited role, imaging rates are high; $39 \%$ of patients with low back pain are referred for imaging by general practitioners in Norway, ${ }^{42} 54 \%$ in the USA, ${ }^{27}$ and $56 \%$ in Italy. ${ }^{41}$ Although guidelines discourage the use of opioids, they are widely used in many high-income countries, especially in, but not limited to, North America. ${ }^{55,72}$ Although data for effects of opioids for acute low back pain are sparse, ${ }^{73}$ one study showed that they were prescribed for around $60 \%$ of emergency department presentations for low back pain in the USA. ${ }^{55}$ More than half the total number of people taking opioids long-term have low back pain,$^{72}$ although no randomised controlled trial evidence is available about long-term effects. ${ }^{73,74}$ Surgery has, at best, a very limited role for low back pain, but studies from the USA, ${ }^{59}$ Australia, ${ }^{63}$ and the Netherlands ${ }^{62}$ show frequent use of spinal fusion. Interventional procedures are also overused, with studies showing 990449 lumbar or sacral facet injections and 406378 lumbar or sacral facet neurotomy procedures funded by Medicare in the USA in 2011. ${ }^{60}$

The waste of health-care resources is an obvious consequence of overuse, but implications for patients also exist. The most obvious consequence of unnecessary lumbar imaging is exposure to radiation, but studies also suggest that more liberal use of imaging triggers additional medical care (eg, additional testing, specialist referral, surgery, and interventional procedures) and increases the risk of adverse outcomes, such as absence from work..$^{75}$ The most disturbing risks related to use of opioids are addiction, overdose, and death. In the USA, prescription opioid-related deaths were around 15000 in $2015 .{ }^{76}$ The growing use of complex fusion procedures in patients older than 60 years undergoing decompressive surgery for spinal stenosis is concerning, since fusion operations are three times more expensive than decompression alone, and have double the rates of wound complications, cardiopulmonary complications (such as stroke), and 30-day mortality." Importantly, trials have clarified that adding fusion to decompressive surgery for symptomatic spinal stenosis does not improve outcomes. $^{78}$

Even in high-income countries, access to best practice can be constrained by availability (eg, in rural and remote regions), payment models (eg, health-care systems' 
coverage of medication and surgery, but not physical and psychological treatments), and patients' uncertainty about when or where to seek care. ${ }^{79}$ A systematic review of 21 studies from 12 countries, four of which were mediumincome (Cambodia, Cameroon, Barbados, Brazil), and eight high-income (Australia, Canada, Greece, Italy, France, Spain, the USA, and the UK) showed that many people go straight to emergency departments for their low back pain..$^{80}$ The authors estimated the prevalence of low back pain in the emergency department setting to be $4 \cdot 39 \%$ (95\% CI 3.67-5.18), similar to that of shortness of breath and fever and chills. ${ }^{80}$ Many high-income countries, such as Australia and Canada, have culturally diverse populations with both an indigenous population and a large migrant population. The guideline-recommended treatments present real challenges in these diverse populations; for example, delivery of cognitive behavioural therapy or mindfulness-based stress reduction could be challenging if the therapist does not speak the same language as the patient, or does not appreciate the various ways low back pain could be conceptualised in different cultural groups.

For low-income and middle-income countries, although much less published evidence is available about current practice for low back pain, available data show that gaps between evidence and practice are also apparent in these countries (panel 1). ${ }^{35}$ For example, in Cambodia, ${ }^{30}$ Brazil, ${ }^{31}$ and Argentina, ${ }^{33}$ it is not uncommon for people with low back pain to present to the emergency department and then stay in hospital for several days. The previously mentioned systematic review of low back pain in the emergency department showed that middle-income countries have prevalences that are similar to those in high-income countries (eg, Cambodia 5.6\%, Italy $4.9 \%)$. $^{80}$ In Iran, ${ }^{29}$ most people with low back pain consult with specialists (eg, an orthopaedic surgeon, neurosurgeon, or rheumatologist) in view of the paucity of patient referral systems from general practice. A South African study ${ }^{35}$ showed that $90 \%$ of patients with low back pain seen in primary care received pain medicines as the only form of treatment. Imaging rates for low back pain also seem to be inappropriately high in several low-income and middleincome countries, including India, ${ }^{44}$ China,${ }^{45}$ Iran, ${ }^{46}$ Brazil, ${ }^{40}$ and Russia, ${ }^{47}$ and although the availability of published data is limited, those that are available (from Brazil) suggest large increases in spinal surgery costs over the past 20 years. ${ }^{65}$

The paucity of comparative data makes comparisons of high-income, low-income, and middle-income countries challenging. However, the examples in panel 1 seem to suggest greater use of advice to rest and of passive electrical modalities in low-income and middle-income countries. In all countries, access to structured exercise programmes is variable, and poor access to cognitive behavioural therapy and multidisciplinary rehabilitation programmes remains a barrier to widespread use. ${ }^{81}$ Clear evidence exists of lower consumption of opioids in low-income and middle-income countries than in high-income countries; but examples exist of high-income countries (eg, Japan) that have very low rates of opioid use, so the high consumption in countries such as the USA and Canada is not fully explained by the countries' wealth. The above information shows that many of the mistakes of high-income countries are already well established in low-income and middle income-countries. Initiatives are urgently needed that both reduce low-value health care for low back pain and help health-care professionals, patients, and policy makers make decisions more in line with best available evidence. The following section provides examples of effective, promising, and emerging directions.

\section{Promising directions}

Examples of effective, promising, and emerging solutions that target health care, public health, or both, are summarised in table 3. We particularly searched for examples from low-income and middle-income countries but found very few assessments of solutions within these countries that suggest they might offer helpful alternatives to current care. More data are urgently needed about effective and affordable strategies for prevention and management of low back pain in such countries. In these settings, strategies probably need to be integrated with other musculoskeletal and non-communicable disease initiatives to ensure maximum benefit from available resources. The examples in table 3 are mainly drawn from high-income countries, and for each we have added a judgment about the amount of evidence, which shows that many are still understudied or are confined to single, often observational, studies. Even those judged to be effective have underpinning evidence for effectiveness from only one country, and many were the focus of a research study, and not implemented or tested in new contexts outside a research setting. Therefore, important questions remain about effectiveness, cost-effectiveness, and scalability of these innovations.

\section{Implementation of best available evidence}

That guidelines without effective strategies to implement their recommendations have little or no effect on clinical practice has been repeatedly shown. Implementation strategies need to be tailored to overcome specific barriers to change $\mathrm{e}^{106}$ and feature education and training, social interaction, clinical decision support systems, and targeted reminders. ${ }^{107,108}$ Some of the key challenges to implementing best practice for low back pain are known, including short consultation times, clinicians' poor knowledge of and misconceptions about clinical guidelines, fear of litigation in the event of missed, rare, serious pathology, and a desire to maintain harmonious relationships with patients. ${ }^{108}$ Yet, successful examples exist of focused guideline implementation efforts (table 3). In the USA and UK, approaches that better support clinical decision making have changed clinical practice; use of a special radiograph requisition form that 
Panel 1: Gaps between evidence and practice in the management of low back pain

\section{Guideline message: low back pain should be managed in primary care}

Practice: in high-income, low-income, and middle-income settings, people with low back pain present to emergency departments or to a medical specialist

\section{High-income settings}

- A 2003 study of an emergency department in Paris, France, found that the proportion of presentations in which low back pain was the primary complaint was $11.0 \%{ }^{24}$

- In Victoria, Australia, between 2009 and 2012, 14568 calls were made to 000 for an emergency ambulance for low back pain; in $22.3 \%$ of these cases, an emergency ambulance was dispatched and in 38.8\%, a non-emergency ambulance was dispatched ${ }^{25}$

- In the 10 years from 2004-05 to 2013-14, the age-standardised rate of admissions to hospital for back problems in Australia increased by $20 \%{ }^{26}$

- Low back pain results in 2.6 million visits to emergency departments a year in the USA ${ }^{27}$

- Of the 944 presentations for low back pain to an Italian emergency department in a year, six $(0.6 \%)$ were diagnosed with a condition that was regarded as an emergency (defined as associated with high morbidity or mortality risk, requiring prompt assessment and hospital admission $)^{28}$

Low-income or middle-income settings

- A 2011 study showed no patient referral system existed in Iran: most patients with acute or chronic low back pain visit directly an orthopaedic surgeon, neurosurgeon, or rheumatologist, rather than visiting general practitioners ${ }^{29}$

- A 2012 study of two emergency departments in Cambodia showed that the primary complaint was low back pain in 5.6\% of the 1295 presentations (11th most common complaint); $41 \%$ of patients with low back pain were admitted ${ }^{30}$

- A 2009 study of an emergency department in Brazil showed that musculoskeletal conditions were the most common presentation, with low back pain the leading condition ${ }^{31}$

- The 2011 National Health and Wellness Survey in Brazil estimated that 16.8 million Brazilians had had low back pain; of these, $16.7 \%$ had been admitted to hospital in the past 6 months and $36.5 \%$ had visited an emergency department (rates were $8.8 \%$ and $19.74 \%$, respectively, for those not having low back pain) ${ }^{32}$

- In Argentina, in 2006 to 2010, the most common reason for admission to hospital for a musculoskeletal condition was low back pain and the mean length of stay was 3.8 days $^{33}$

\section{Guideline message: provide education and advice}

Practice: in high-income, low-income, and middle-income settings, this aspect of care is rarely provided
High-income settings

- Advice was provided at only $21 \%$ of consultations with a general practitioner in Australia ${ }^{34}$

Low-income or middle-income settings

- A 2014 survey in Community Health Centres in Cape Town, South Africa, reported that only 101 (23.3\%) of 433 patients with low back pain reported receiving education about predisposing factors ${ }^{35}$

Guideline message: remain active and stay at work Practice: in high-income, low-income, and middle-income settings, many clinicians and patients advocate rest and absence from work

High-income settings

- Three surveys of Australian general practitioners in the period $1997-2004$ revealed that $24.5 \%$ of them who had a special interest in low back pain, endorsed the incorrect view that "Patients should not return to work until they are almost pain free" compared with $15 \cdot 8 \%$ of those who did not have a special interest ${ }^{36}$

- A 2012 survey of primary care patients with low back pain in Qatar revealed that the most common treatment was bed rest $(67 \cdot 2 \% \text { of } 1829 \text { patients })^{37}$

Low-income or middle-income settings

- A 2008 survey of all registered physiotherapists in the state of Maharashtra, India, ( $n=186,70 \%$ response rate) showed that $46 \%$ of physiotherapists advised patients with low back pain to rest ${ }^{38}$

- $63 \%$ of Indians believe that bed rest is the mainstay of therapy ${ }^{39}$

- $90 \%$ of Brazilian rheumatologists advised patients with acute low back pain to rest ${ }^{40}$

- In Iran, "extended bed rest and reduction of physical activity are generally recommended by many clinicians, especially for patients with acute episodes of low back pain"29

Guideline message: imaging should only occur if the clinician suspects a specific condition that would require different management to non-specific low back pain Practice: although such specific causes of low back pain are rare, in high-income, low-income, and middle-income settings, imaging rates are high

High-income settings

- Imaging was done for $56.4 \%$ of 746 patients who presented with low back pain to an emergency department of an Italian academic hospital in $2013^{41}$

- A 2011 Norwegian study showed that 38.9\% of patients with low back pain were referred for imaging by their general practitioner ${ }^{42}$

(Continues on next page) 
(Panel 1 continued from previous page)

- In the USA, a study of insurer data revealed that the rate of imaging for low back pain without red flag conditions was not influenced by the Choosing Wisely campaign: the baseline rate in 2010 was $53.7 \%$ (95\% Cl 52.5-54.9), and by the end of 2013 it was exactly the same, at $53.7 \%$ $(52 \cdot 5-54 \cdot 9)^{27}$

- A survey of all Australian chiropractors ( $n=4859$, $10 \%$ response rate) showed that $54 \%$ agreed that lumbar radiography is indicated for acute low back pain ${ }^{43}$

Low-income or middle-income settings

- A prospective study in the period 2008-10, of 251 patients with chronic low back pain reviewed in an Indian orthopaedic clinic, reported that $100 \%$ of patients underwent imaging, with $76 \%$ diagnosed with non-specific low back pain and $10 \%$ with spondylosis ${ }^{44}$

- A review of the lumbar spine MRI scans of 3107 patients from Hangzhou, eastern China, in 2013, showed that simple back pain was the most common reason for ordering an MRI $(41 \cdot 3 \%)^{45}$

- 400 consecutive patients with low back pain referred to four radiology clinics for MRI scans in Tehran, Iran, in 2012, completed a questionnaire to establish if the imaging was indicated; of these, only 187 (46.7\%) had an indication for $\mathrm{MRI}^{46}$

- $70 \%$ of Brazilian rheumatologists order imaging at first visit for a patient with acute low back pain ${ }^{40}$

- A study in hospital outpatients with low back pain in Moscow, Russia, ( $n=1300$ ) concluded that the most frequent diagnostic method used was radiography of the spine $\mathrm{s}^{47}$

\section{Guideline message: first choice of therapy should be} non-pharmacological

Practice: surveys of care show that this approach is usually not followed

High-income settings

- A survey of Australian general practice care from 2000 to 2010 (21350 patient encounters) showed that $64.5 \%$ of patients were prescribed a medicine at the first visit for a new episode of low back pain ${ }^{48}$

- A potential reason is the way in which health-care systems preferentially fund surgery and medicines over physical and psychological therapies

Low-income or middle-income settings

- $90 \%$ of primary care patients in South Africa received pain medicines as their only form of treatment ${ }^{35}$

- A potential reason is that health-care systems do not have the capacity to deliver non-pharmacological care

Guideline message: most guidelines advise against electrical physical modalities (eg, short-wave diathermy, traction)

Practice: worldwide these ineffective treatments are still used by the professionals who administer physical therapies
High-income settings

- A survey of Swedish physiotherapists ( $n=271,65 \%$ response rate) showed that around $38 \%$ advocated transcutaneous electrical nerve stimulation for low back pain ${ }^{49}$

- A 2013 survey of US orthopaedic physical therapists ( $n=1001,25 \%$ response rate) showed that $75 \%$ used lumbar traction $^{50}$

- A 2009 survey in three Australian states $(n=203$, $36 \%$ response rate) asked for treatment choices for five patient vignettes and showed that $17-34 \%$ of physiotherapists advocated physical modalities for low back pain depending on the vignette ${ }^{51}$

- A study of Spanish National Health Service data for 2004-07 showed that 38.6\% of expenditure for physical therapies was for treatments that are known to be ineffective ${ }^{52}$

Low-income or middle-income settings

- A 2008 survey in the state of Maharashtra, India, ( $n=186$, $70 \%$ response rate) showed that physical modalities were the first treatment preference of $33 \%$ of all registered physiotherapists ${ }^{38}$

- A 2000 survey of Thai physiotherapists ( $n=559$, $77 \cdot 2 \%$ response rate) reported that $61.2 \%$ advocated ultrasound for low back pain and $61.0 \%$ advocated traction ${ }^{53}$

- A survey of practice in Ghana showed that over $60 \%$ of treatment sessions included multiple therapies (exercises, advice, massage, electrotherapy, and manual therapy $)^{54}$

Guideline message: due to unclear evidence of efficacy and concerns of harm, the use of opioid analgesic medicines is now discouraged

Practice: these medicines have been overused in some, but not all, high-income countries; low-income and middle-income countries seem to have very low rates of use

High-income settings

- In 2009, opioids were prescribed for around $60 \%$ of presentations to emergency departments for low back pain in the USA ${ }^{55}$

- An Italian study of 746 patients with low back pain presenting to an emergency department showed that $42 \%$ were prescribed an opioid ${ }^{41}$

- A 2006 US population-based survey of people with chronic low back pain ( $n=706$, mean pain duration 9.8 years), showed that of those who had seen a provider in the past year, $47.0 \%$ had taken a strong narcotic and $32.8 \%$ a weak narcotic ( $60.5 \%$ took some sort of narcotic) in the month before survey; of those who had not seen a provider, $5.9 \%$ had taken a strong narcotic and $14.7 \%$ had taken a weak narcotic ${ }^{56}$

- A 2004 US study based on health-care insurer data of 26014 patients with low back pain managed in primary care, showed that $61.0 \%$ were prescribed an opioid and $18.8 \%$ were on long-term opioid therapy ${ }^{57}$

(Continues on next page) 
(Panel 1 continued from previous page)

Low-income or middle-income settings

- Low-income and middle-income countries typically have low consumption of opioids (eg, in 2015 , prescription of opioid medicines in Africa was $2.0 \mathrm{mg} /$ head of population vs $677.0 \mathrm{mg} /$ head of population in the USA) ${ }^{58}$

Guideline message: interventional procedures and surgery have a very limited role, if any, in the management of low back pain

Practice: these approaches are used widely in high-income countries; little evidence on their use is available for low-income and middle-income settings

High-income settings

- In the USA, in 2011, spinal fusion was responsible for the highest aggregate hospital costs of any surgical procedure (US $\$ 12.8$ billion) $)^{59}$

- 990449 lumbar or sacral facet injections and 406378 lumbar or sacral facet neurotomy procedures were funded by US Medicare in $2011^{60}$

- 252654 sacroiliac joint injections were funded by US Medicare in $2011^{61}$

- A survey of Dutch spinal surgeons (132 active surgeons surveyed, $70 \%$ response rate) showed that two-thirds do spinal fusion procedures for low back pain ${ }^{62}$

- In Australia from 2003 to 2013, the fastest increasing surgical procedure for spinal stenosis was complex fusion, although the surgery provides no added benefit compared with decompression alone, and is more costly and associated with greater harms ${ }^{63}$

- Use of epidural injections increased substantially in the US Medicare population from 2000 to 2011, with 2023481 epidural injections funded in $2011^{64}$

Low-income or middle-income settings

- In the period 1995-2014, in Brazil, the cost of spine surgeries increased by $540 \%$ (from $R \$ 27 \cdot 1$ million to $\$ 146.5$ million $)^{65}$
Guideline message: exercise is recommended for chronic low back pain

Practice: clinician treatment preferences and health-care constraints limit uptake

High-income settings

- $54 \%$ of people with chronic low back pain in the USA had not been prescribed exercise ${ }^{56}$

- Australia's universal health-care system, Medicare, has a limit of five allied health consultations, which is too few to deliver a typical exercise programme for chronic low back pain ${ }^{6,67}$

Low-income or middle-income settings

- A survey of Ghanaian physiotherapists revealed wide endorsement of exercise for patients with chronic low back pain ${ }^{54}$ but access is limited by out-of-pocket costs to the patient ${ }^{68}$

Guideline message: a biopsychosocial framework should guide management of low back pain

Practice: the psychosocial aspects of low back pain are poorly managed in high-income, low-income, and middle-income settings

High-income settings

- Only $12 \%$ of people with chronic low back pain with depression in the USA had seen a psychiatrist or psychologist in the previous year ${ }^{56}$

- Only $8.4 \%$ of patients with low back pain in the USA were prescribed cognitive behavioural therapy ${ }^{69}$

Low-income or middle-income settings

- "Structured assessment of psychosocial factors is not part of routine management of low back pain in Iran, mainly because of absence of standard instruments" ${ }^{\prime 2}$

- "Management of patients with low back pain in Iran is dominantly based on a traditional biomedical model and therapeutic interventions based on a biopsychosocial approach are implemented only in a few university-affiliated physical therapy clinics" ${ }^{\prime 2}$ allowed only three guideline-appropriate indications led to a $36 \cdot 8 \%$ reduction in lumbar spine imaging, ${ }^{82}$ and the addition of short educational messages to all reports of lumbar spine MRIs significantly reduced imaging rates by $22 \cdot 5 \% .{ }^{83}$ In Denmark, a multifaceted implementation strategy consisting of outreach visits, reports about the quality of care, and a self-completed questionnaire to help general practitioners to identify patients' risk of persistent pain led to reduced referral to secondary care and was cost-saving. ${ }^{84,85}$ Reviews have shown no differences in effect on practice between multifaceted strategies compared with minimal, single, or no implementation strategy, ${ }^{109}$ and the ineffectiveness of one-off implementation efforts, such as a single educational event. ${ }^{110}$ Rather, it seems that implementation efforts need regular repetition or to be continuous to effectively change practice for low back pain. ${ }^{110}$ Key challenges include identifying ways to remove existing unhelpful but well established practice patterns, and identify the most effective and cost-effective implementation strategies that ensure improvements are sustained over time. Very few randomised trials of implementation strategies have assessed costs. ${ }^{111}$ Tough policy decisions are also needed that reduce the unhelpful influence of industry and reduce or remove reimbursement for lowvalue care.

Improved and better integrated education of health-care professionals could support implementation of best practice for low back pain, help to break down professional barriers, develop a common language, and create new and innovative strategies for practice. ${ }^{112}$ Examples of such support include, the integrated education of medical 


\section{Health care}

Focused effort to implement guideline recommendations

USA $^{8}$

Clinical decision support using a special radiographic requisition form for emergency room house officers to use to request lumbar spine radiographs. The new form was introduced, allowed only three guideline-appropriate indications for radiographs, and had to be used for a patient to have a radiograph. The implementation strategy was simple but ongoing in nature. The primary outcome was the number of imaging referrals.

$\mathrm{UK}^{83}$

Audit and feedback, and targeted reminder messages attached to all reports of lumbar spine MRI sent to 243 general practices. Control group received guideline dissemination. General practitioners' patients' records were examined for concordance with the guidelines. The primary outcome was number of radiograph requests per 1000 patients per year. ${ }^{83}$

Denmark ${ }^{84,85} \quad$ Multifaceted implementation strategy with 60 general practices and 1101 patients. The strategy consisted of outreach visits, reports about quality of care, and the STarT Back Tool to identify patients' risk of persistent disabling pain. The control group received usual implementation approach. The aim was to reduce the proportion of patients being referred from primary care to secondary care within the first 12 weeks.

Change clinical systems and pathways for low back pain

$\mathrm{UK}^{86-88}$ Stratified primary care based on the patient's risk of persistent disabling pain (STarT Back). The approach consists of the use of a short self-completed questionnaire (the STarT Back tool) ${ }^{86}$ to identify the patient's risk subgroup (low, medium, or high risk) with treatment then matched to the subgroup. The STarT Back trial ${ }^{87}$ included 852 patients and the IMPaCT Back study included 922 patients. ${ }^{88}$ The primary outcome was back-related disability.

Canada $^{89-91}$ Develop a systematic and multidisciplinary care pathway for low back pain to reduce variation in practice, improve quality, and access to care. The Saskatchewan Spine Pathway (SSP) has three components: (1) guideline-based education for clinicians (including a continuing medical education course with linked financial incentives) and education for patients; (2) specialised spine pathway clinics for patients who do not improve, supported by structured referral forms and staffed by specially trained physiotherapists that triage patients for further therapy, imaging, or referral to a spine surgeon; and (3) outcomes research. Key outcomes include pain, disability, waiting times, imaging, and referral to spine surgeon. first-line care to specialised care. The NHS England National Low Back and Radicular Pain Pathway developed by 30 stakeholder groups reached agreement on a uniform care pathway. Key to the pathway is the role of the specialist triage practitioner (predominantly specialist physiotherapists or nurses) and the availability of a comprehensive multidisciplinary combined physical and psychological programme. $^{94}$
Reduction in radiograph requests from 1443 to 759 . The authors concluded that a $47 \%$ reduction in lumbar spine radiographs occurred in the first year, which they reported was maintained for the next 3 years. ${ }^{82} \mathrm{~A}$ re-analysis of the study data, taking into Promising: one study of interrupted time series design, which did not patients. Unknown readiness for account the time series design, estimated a significant decrease in large-scale implementation. imaging of $36 \cdot 8 \%(95 \% \mathrm{Cl} 33 \cdot 2-40 \cdot 5)$.

Routine attachment of educational reminder messages to imaging reports led to an absolute change of -1.53 per 1000 patients $(95 \% \mathrm{Cl}-2.5$ to -0.57$)$ from 6.8 per 1000 patients in the control group, a reduction in imaging of $22.5 \%$ ( $95 \% \mathrm{C}$ 8.4 to 36.8$)$.

27 patients $(5.0 \%)$ in the intervention group were referred to secondary care versus 59 patients $(10.5 \%)$ in the control group (OR 0.52, 95\% Cl 0.30-0.90; $\mathrm{p}=0.020$ ). The strategy saved $£ 93.20$ per patient ( $£ 406.51$ vs $£ 499.71$ ). The implementation strategy resulted in lower patient satisfaction (OR $0.50,95 \% \mathrm{Cl}$ $0.31-0.81 ; p=0.004)$.

Stratified primary care led to significantly improved back-related disability and improvements in other outcomes such as days lost from work. There were also changes in health-care use (less spinal imaging, fewer repeat visits to general practice, fewer specialist consultations) that contributed to cost savings of $£ 34$ (US\$50) pe patient in health-care costs, and $£ 600$ ( $\$ 877)$ per employed patient when days lost from work were included.

The clinic triaged patients for (1) non-surgical management or (2) referral to spine surgeon. Use of the SSP resulted in $71.3 \%$ of patients discharged after education, self-care advice, and conservative care compared with $28.7 \%$ of those referred to a surgeon. MRI use was significantly reduced $(25.8 \%$ in patients discharged after conservative care compared with $92.0 \%$ in patients referred to surgeons). Use of the SSP did not result in different disability scores compared with patients managed as usual, but it led to shorter waiting times for MRI and surgical assessment, and greater proportions of patients referred to surgeons that were judged as suitable candidates for surgery.

As of February, 2017, the pathway's free implementation pack (generic business case, value impact assessment, cost-saving calculator, training support, information technology support, step-by-step guide) had been downloaded by $30 \%$ of clinical commissioning groups in England with 15 actively implementing the Pathway. Early assessment in the northeast of England shows significant improvement in patient management, and in pain, disability, and mental health outcomes, high patient satisfaction, and significant reductions in community physiotherapy, radiographs, MRI scans, and referrals to secondary care. Wider national implementation is overseen by the NHS Trauma Programme of Care and the Spinal Services Clinical Reference Group.
Promising: one randomised controlled trial (of before-and-after cluster readiness for large-scale implementation.

Effective: one cluster randomised controlled trial with linked cost-effectiveness analysis. Potential for testing in other countries and settings.

Effective: two studies, one randomised controlled trial with linked cost-effectiveness analysis and one impact analysis sequential cohort study with linked cost-effectiveness analysis. Potential for testing in other countries and settings.

Emerging: one retrospective analysis of 87 consecutive patients through the $\mathrm{SSP}_{,}^{89.90}$ and one retrospective medical record review of 215 referrals..$^{91}$ Unknown readiness for large-scale implementation.

Emerging: one before-and-after study summarised in a report for the UK NHS, further assessments are continuing but are also of observational (before-and-after) study design. Unknown readiness for large-scale implementation. randomised design). Unknown

(Table 3 continues on next page)

doctors with chiropractors in Denmark; ${ }^{112,113}$ the Centers for Excellence in Pain Education, funded by the National Institutes of Health in the USA that include e-learning modules focused on interactivity, expert modelling, and feedback; ${ }^{114}$ and the promising results of a training course with Swedish physiotherapists aimed at identifying and addressing psychosocial obstacles to recovery in patients with low back pain. ${ }^{115}$

\section{Clinical systems and pathways}

A more radical health-care solution is to change the clinical-care model for low back pain. An example of this 


\begin{tabular}{|c|c|c|c|}
\hline & Solution detail & Results & $\begin{array}{l}\text { Strength of evidence* and readiness } \\
\text { for large-scale implementation }\end{array}$ \\
\hline \multicolumn{4}{|c|}{ (Continued from previous page) } \\
\hline \multicolumn{4}{|c|}{ Health care and public health } \\
\hline \multicolumn{4}{|c|}{ Integrate health and occupational interventions } \\
\hline USA $^{95}$ & $\begin{array}{l}\text { Quality improvement intervention of financial incentives and } \\
\text { organisation support aimed at reducing work disability. } \\
\text { Baseline data included } 33910 \text { workers' compensation claims } \\
\text { (July, 2001, to June, 2003), and post-intervention data } \\
\text { included 71696 patients' data (July, 2004, to June, 2017). } \\
\text { Outcomes at 1-year follow-up included work disability status, } \\
\text { number of disability days, and costs. }\end{array}$ & $\begin{array}{l}\text { Patients were less likely to be off work and on disability at } 1 \text { year } \\
\text { (OR } 0.79 ; p=0.003) \text {. The average reduction in disability days in } \\
\text { patients with back pain was } 29.5 \%(p=0.003) \text {. Total disability and } \\
\text { medical costs were reduced by US } \$ 510 \text { per claim ( } p<0 \cdot 01) \text {. }\end{array}$ & $\begin{array}{l}\text { Emerging: one non-randomised } \\
\text { before-and-after study with } \\
\text { non-equivalent comparison group. } \\
\text { Unknown readiness for large-scale } \\
\text { implementation. }\end{array}$ \\
\hline Sweden ${ }^{96}$ & $\begin{array}{l}\text { Intervention aimed at both workers at risk of long-term } \\
\text { impairments ( } n=140,94 \% \text { female) and the workplaces } \\
\text { ( } 55 \text { supervisors). The intervention was manualised and based } \\
\text { on cognitive behavioural therapy principles, and involved } \\
\text { communication and problem-solving skills for both the } \\
\text { worker and supervisor. The control received evidence-based } \\
\text { treatment as usual. }\end{array}$ & $\begin{array}{l}\text { The intervention showed significantly greater improvements } \\
\text { compared with the control, in numbers of workers having work } \\
\text { absence due to pain (intervention<control; } \mathrm{p}<0.05 \text { ), health-care } \\
\text { use (intervention<control; } \mathrm{p}<0.01 \text { ), and perceived health } \\
\text { (intervention }>\text { control; } \mathrm{p}<0.01 \text { ). }\end{array}$ & $\begin{array}{l}\text { Promising: one randomised controlled } \\
\text { trial. Unknown readiness for large-scale } \\
\text { implementation. }\end{array}$ \\
\hline Netherlands $s^{9798}$ & $\begin{array}{l}\text { Integrated care programme for low back pain patients ( } \mathrm{n}=134 \text { ) } \\
\text { sicklisted for at least } 12 \text { weeks, that involved a patient-directed } \\
\text { and workplace intervention (ergonomics, supervisor } \\
\text { involvement, and a graded activity programme based on } \\
\text { cognitive behavioural therapy principles). Control group } \\
\text { received usual care. Outcomes included duration of time off } \\
\text { work until full sustainable return to work and functional status. }\end{array}$ & $\begin{array}{l}\text { Median duration of time off work until full sustainable return to } \\
\text { work was } 88 \text { days in the intervention group vs } 208 \text { days in the } \\
\text { control group }(p=0 \cdot 003) \text {. Integrated care was effective for return to } \\
\text { work (HR } 1 \cdot 9,95 \% \mathrm{Cl} 1 \cdot 2-2 \cdot 8 ; p=0 \cdot 004) \text { and functional status } \\
\text { ( } p=0 \cdot 01) \text { vs usual care control. Total costs in the integrated care } \\
\text { group ( } £ 13165 \text {, SD } 13600 \text { [US } \$ 18229 \text {, SD } 18834] \text { ) were } \\
\text { significantly lower than in usual care }(£ 18475 \text {, SD } 13616 \text { [ } \$ 25660 \text {, } \\
\text { SD } 18856]) \text {. The intervention resulted in a return on investment of } \\
£ 26 \text { for every } £ 1 \text { invested ( } \$ 36 \text { for every } \$ 1 \cdot 39) \text { vs usual care. }\end{array}$ & $\begin{array}{l}\text { Effective: one randomised controlled } \\
\text { trial with health economic evaluation. } \\
\text { Potential for testing in other countries } \\
\text { and settings. }\end{array}$ \\
\hline \multicolumn{4}{|c|}{ Change compensation and disability policies } \\
\hline Netherlands ${ }^{99,100}$ & $\begin{array}{l}\text { Cost of illness study to investigate costs of back pain from } \\
2002 \text { to } 2007 \text {, after introduction of new laws on health } \\
\text { insurance and sickness benefits and new guidelines for } \\
\text { health-care professionals. Data gathered from national } \\
\text { registries, reports of research institutes, descriptive studies, } \\
\text { and occupational health-care authorities. }\end{array}$ & $\begin{array}{l}\text { The total costs of back pain fell from } € 4.3 \text { billion in } 2002 \text { to } \\
€ 3.5 \text { billion in } 2007 . \text { The share of these costs was about } 0.9 \% \text { of } \\
\text { the GNP in } 2002 \text { and } 0.6 \% \text { of GNP in } 2007 \text {. The ratio between } \\
\text { direct and indirect costs did not change noticeably over the } \\
\text { years, that is, } 12 \% \text { for direct and } 88 \% \text { for indirect costs. }{ }^{.00}\end{array}$ & $\begin{array}{l}\text { Emerging: one non-randomised cost- } \\
\text { of-illness study. Unknown readiness for } \\
\text { large-scale implementation. }\end{array}$ \\
\hline \multicolumn{4}{|l|}{ Public health } \\
\hline \multicolumn{4}{|c|}{ Change the beliefs and behaviours of the public through mass-media campaigns } \\
\hline Australia ${ }^{101-103}$ & $\begin{array}{l}\text { In Victoria, Australia, between September, 1997, and } \\
\text { December, 1999, the mass-media campaign Back Pain: Don't } \\
\text { Take it Lying Down was delivered for } 12 \text { months (intense } \\
\text { campaign) followed by a further } 15 \text { months (less intense } \\
\text { campaign). It had widespread endorsement from national } \\
\text { medical bodies and was primarily delivered through television } \\
\text { advertisements aired during prime time, featuring experts, } \\
\text { sports personalities who had successfully managed back pain, } \\
\text { and actors, comedians, and the minister for health. It also used } \\
\text { radio, billboard, and print advertisements, posters, seminars, } \\
\text { visits by well-known personalities to workplaces, and publicity } \\
\text { articles and publications. The campaign's overall cost was } \\
\text { US } \$ 7.6 \text { million. }\end{array}$ & $\begin{array}{l}\text { Improvements in back pain beliefs in Victoria (mean scores on the } \\
\text { Back Beliefs Questionnaire } 26 \cdot 5,28 \cdot 4 \text {, and } 29 \cdot 7 \text { ) but not in } \\
\text { control }(26 \cdot 3,26 \cdot 2 \text {,and } 26 \cdot 3) \text {. Reduction in number of claims for } \\
\text { back pain }(15 \%) \text {, medical payments for claims for back pain } \\
(20 \%) \text {, and rate of days compensated. }\end{array}$ & $\begin{array}{l}\text { Promising: quasi-experimental, } \\
\text { non-randomised, before-and-after } \\
\text { study with an adjacent Australian state } \\
\text { as control group. Potential for testing } \\
\text { in other countries and settings. }\end{array}$ \\
\hline Canada $^{104,105}$ & $\begin{array}{l}\text { In Alberta, Canada, from May, 2005, to December, } 2016 \text {, } \\
\text { a mass-media campaign, Back Active, was delivered. It had } \\
\text { widespread endorsement from local health associations and } \\
\text { featured local health professionals and organisations and an } \\
\text { Olympic gold medallist. The primary medium was radio } \\
\text { advertisements, but also used a website, posters, pamphlets, } \\
\text { bus and billboard advertisements, articles in the public and } \\
\text { industry news, and some television public service } \\
\text { announcements. The campaign's overall cost for the first } \\
3 \text { years was US } \$ 723300 \text {. }\end{array}$ & $\begin{array}{l}\text { Improvements in back pain beliefs in Alberta were observed } \\
\text { since the proportion of participants agreeing with a statement } \\
\text { about staying active rose from } 55 \cdot 5 \% \text { to } 63.4 \% \text { ( } p=0.008 \text { ) with } \\
\text { no change in control in the Saskatchewan population } \\
\text { (consistently } 60 \% \text { ). No effect seen on health-care use (imaging } \\
\text { or visits to health professionals for back pain or work disabling } \\
\text { claims). }\end{array}$ & $\begin{array}{l}\text { Promising: quasi-experimental } \\
\text { before-and-after study with adjacent } \\
\text { Canadian province as a control. }\end{array}$ \\
\hline
\end{tabular}


is a new model of stratified primary care for non-specific low back pain known as STarT Back that involves two components; first, a brief self-completed questionnaire to identify patients' risk of persistent disabling pain (low, medium, or high risk) ${ }^{86}$ and second, treatments that are matched to each risk subgroup. Summarised in table 3 are two studies within the UK's National Health Service (NHS) that have shown stratified care to be more effective than a best care comparison group,${ }^{87}$ and more cost-effective than usual primary care. ${ }^{88}$ On the basis of this evidence, the current UK clinical guideline now recommends risk stratification. ${ }^{8}$ Stratified care approaches, such as STarT Back, that target resources to those most likely to benefit might allow more effective prioritisation of health-care resources.

Another potential health-care solution is to reconfigure, with agreement from all stakeholders, the whole clinical pathway from care at first contact through to specialised care. A clinical pathway has been defined as a "complex intervention for the mutual decision-making and organisation of care processes for a well-defined group of patients during a well-defined period"116 and "an integrated, multi-disciplinary strategy to organise the timing, sequencing, and coordination of care to optimise patient outcomes and enhance efficiency" ${ }^{117}$ A major barrier to changing clinical pathways relates to current models of health-care reimbursement, which reward volume rather than quality, perversely providing remuneration not for how effectively patients are treated, but for how much they are treated. ${ }^{118}$ A 2011 systematic review of clinical pathways for low back pain identified four pathways, but none had outcome data available. ${ }^{89}$ Since then, several further care pathways have been developed and implemented with some evaluation, albeit of weak design (table 3). An emerging example from Canada, the Saskatchewan Spine Pathway, is a co-ordinated multidisciplinary pathway that seems to reduce both requests for MRI and referrals to spinal surgery, and results in appropriate candidates for surgery being referred to spine surgeons..$^{90}$ In the UK, NHS England's national pathway for treatment of low back and radicular pain was first published in June, 2014, and updated in February, 2017.92 The pathway was agreed by 30 stakeholders, is being implemented in many Clinical Commissioning Groups (NHS organisations that organise the delivery of NHS services in England, each typically responsible for services for around 300000 people), with emerging evidence of benefits for patients and the healthcare system..$^{93}$

Integrate health and occupational interventions A further promising direction could be to target both the health-care system and, more broadly, public health through integrated health-care and occupational interventions. If back pain symptoms are reduced, then return to work is expected to follow. The association between pain, function, and return to work is, however, weak with reviews suggesting that the association changes with low back pain duration (positive association in the acute phase, no association in the subacute phase, and negative association in the chronic phase). ${ }^{119,120}$ People can improve in function and return to work even if pain remains, and evidence shows that return to work occurs before symptom recovery. ${ }^{121}$ Therefore, health-care and occupational health interventions should be considered together in people with low back pain and work disability issues. Examples are available from the USA and Sweden of integrated and early interventions that shift the focus to problem-solving at work, and lead to fewer disability days, earlier return to work, and reductions in use of health care. ${ }^{95,96}$ The new Department of Health Framework and Strategy for Disability and Rehabilitation Services in South Africa ${ }^{122}$ includes goals to integrate comprehensive disability and rehabilitation services within priority health programmes and to foster intersectoral collaboration to address social determinants of ill health. Although low back pain is not specifically mentioned, opportunities could exist for inclusion of low back pain within their stated priority programmes of District Health Services and Health Promotion. Whether integration of health and occupational care is possible or desirable in low-income and middle-income countries with high reliance on temporary and unstable jobs, where little or no protection of employment due to low back pain exists, and where many depend on their pain as a source of income, is unknown. However, data provide evidence of the benefits of a participatory return-to-work programme for this group of workers in the Netherlands, ${ }^{123}$ where the programme resulted in twice as high a rate of return to work and greater societal benefit (€2073 per worker) compared with usual care. Individuals with higher annual income seem more likely to believe that one should stay active during an episode of low back pain;124 therefore, specific targeted interventions need to be developed and tested for those from lower socioeconomic groups to reduce health disparities, address barriers to reintegration into the workforce, and facilitate getting out of poverty.

Multisystem approaches to returning and staying at work could reduce the economic and societal burden of work disability pensions due to low back pain. The example provided in table 3 is of a Dutch integrated care programme for patients with low back pain on long-term disability benefits (on average 5-6 months) that resulted in twice as high a return to work rate, 4 months earlier sustainable return to work, and a return on investment of $£ 26$ for every $£ 1$ invested compared with usual care. ${ }^{97,98}$

Changes to compensation and disability policies offer another potential solution. Substantial differences exist between countries in the prevalence of claims for disability benefits related to back pain, with the back claim rate in the USA being 60 times higher than in Japan, ${ }^{12.5}$ and musculoskeletal claims between states in Brazil being five to six times greater within highly developed states. ${ }^{126}$ One of the first studies ${ }^{127}$ to document the effect of compensation systems on claims for back pain showed in 
Canada that changing from a tort compensation insurance system with payments for pain and suffering to a no-fault system without such payments, led to a decrease in the incidence of claims and time to claim closure. An Australian study showed worse health outcomes in a faultbased system in New South Wales compared with a nofault system in Victoria. ${ }^{128}$ In Brazil, providing a large amount of income replacement $(>100 \%$ ) from the National Social Security Institute resulted in workers with musculoskeletal pain claiming benefits for longer. ${ }^{129}$ Making changes to compensation systems aligns with recommendations from the Organisation for Economic Co-operation and Development (OECD). ${ }^{130,131}$ The effect of different compensation policies on return to work and claim duration is evidenced by an Australian study of allcause work disability claimants, ${ }^{132}$ and a six-country study of 2825 compensation claimants with chronic low back pain who were off work for 3-4 months. ${ }^{133}$ In the six-country study, sustainable return to work rates ranged widely between countries, from $22 \%$ in Germany to $62 \%$ in the Netherlands. The differences were largely due to the Dutch compensation system encouraging greater work interventions than did those of the other countries. The effects of the reform of the Dutch system (panel 2 and figure), in line with OECD recommendations, are evidenced by reductions in sickness absence and disability pensions for back pain from 2002 to $2007.99,100$ Although the absence of a control comparison is a limitation, this multisystem solution from the Netherlands is one that other countries could consider emulating. The Netherlands' approach, and a 2017 international evidence synthesis,$^{134}$ highlight the need for, and power of, policy changes that encourage work interventions supported by less strict compensation policies for disability benefits.

\section{Public health interventions}

Approaches that target public health also offer a possible solution. Public health interventions aim to change the public's back pain beliefs and behaviours. Mass-media campaigns about back pain have been studied in four high-income countries (Australia, ${ }^{101}$ Scotland, ${ }^{135}$ Norway, ${ }^{136}$ and Canada $^{104}$ ), and have proved to have some success (table 3). The campaign in Alberta, Canada, had a modest effect on the public's beliefs (regarding the importance of staying active) compared with a control population, ${ }^{104}$ with positive effects on beliefs persisting 7 years after the initial assessment, with annual bursts of campaign activity. ${ }^{105}$ The Australian mass-media campaign resulted in changes to beliefs and behaviours. ${ }^{102,103}$ The campaign was well funded, predominantly used television commercials featuring recognisable spokespeople, provided practical information about how to stay active and at work despite pain, and had clinical, employer, and employee organisations as partners. Perhaps most importantly, supportive laws and public policies were in place, including financial penalties for employers who did not provide modified work options to employees with back pain. Mass-media campaigns with a
Panel 2: Case study: policy reform in the Netherlands

In the past two decades, new health insurance and sickness benefit laws in the Netherlands have required employers to (1) pay $70-100 \%$ wages to their sick employees for 2 years, and (2) make a return-to-work plan agreed by employer and employee, detailing all actions for the employer and employee. Medical assessments for work disability benefits are postponed to 2 years after reporting sick to give the employee and employer the opportunity to achieve full and sustainable return to work. After 2 years, an independent medical assessment is done to decide on the full benefit for workers with complete sustainable work disability, or on a partial and temporary benefit-based on limitations in functional abilities-for workers who are temporarily or partly disabled; this group is stimulated by financial incentives to resume work for their remaining work capacity. These changes led to a large drop in sickness absence and disability pensions ${ }^{99}$ In line with these reductions, sick leave for low back pain fell by a third between 2002 and 2007 (figure). The total costs of back pain fell from $€ 4.3$ billion in 2002 to $€ 3.5$ billion in 2007. ${ }^{100}$

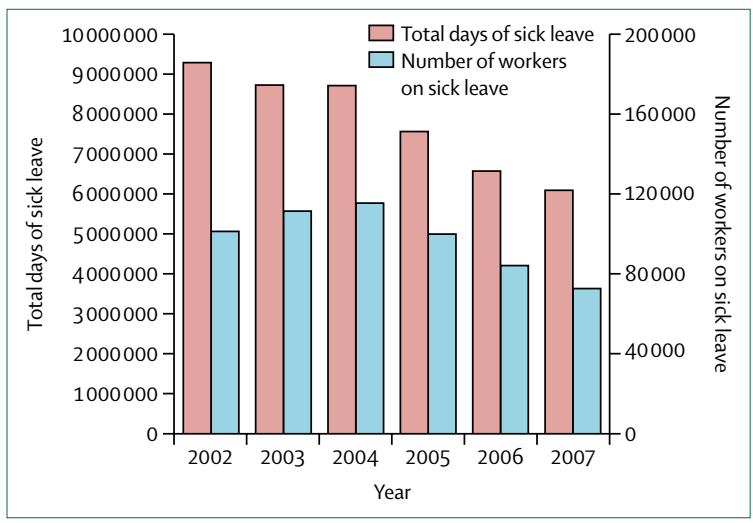

Figure: Sick leave days and number of workers on sick leave in the Netherlands (2002-07)

Reproduced from Lambeek et al, ${ }_{100}^{100}$ with permission from Wolters Kluwer Health.

clear focus on behaviours rather than beliefs alone, and that incorporate new ways to disseminate information, such as personalised marketing, social networks, and customised digital communications, could be considered. Such campaigns might be less expensive than traditional media, and allow more direct access to the public and greater targeting of messages.

Public health strategies are likely to be especially important for low-income and middle-income countries, ${ }^{137}$ where, to date, greater focus and resources have centred on prevention and public health campaigns in infectious diseases. An example strategy in villages in rural Tibet, where $34 \%$ of people reported low back pain, consisted of training in back pain prevention and management in combination with a stand to support water containers. The intervention eased the burden of 
collecting water with the potential to also reduce back pain prevalence and associated disability. ${ }^{138}$ In South Africa, information about back health has been integrated into the Western Cape on Wellness project, promoting healthy lifestyles to reduce the burden of non-communicable diseases across community, work, and school settings. ${ }^{139}$ However, we could not find any assessments or published data for the effectiveness of public health interventions for low back pain in lowincome or middle-income countries.

\section{Conclusions}

Despite many clinical guidelines with similar recommendations for the management of low back pain, the gap between evidence and practice is pervasive. We have provided examples of effective, promising, and emerging directions that deserve greater attention and more rigorous assessment. Even the solutions judged effective draw on limited evidence, but they could potentially be replicable and cost-effective in other settings. Focusing on key principles, such as the need to reduce unnecessary health care for low back pain, support people to be active and stay at work, and reform unhelpful patient clinical pathways and reimbursement models, could guide next steps. The starting point in high-income countries will be different from low-income and middle-income countries, and their priorities are likely to differ. No single solution will be effective, and a collective, global effort will take time, determination, and organisation. Without the collaborative efforts of people with low back pain, policy makers, clinicians, and researchers necessary to develop and implement effective solutions, disability rates, and expenditure for low back pain will continue to rise.

\section{Contributors}

$\mathrm{NEF}$, CGM, and DC were part of the team that developed the original proposal for the Series and coordinated production of papers. All authors drafted key sections of the paper, and NEF and CGM revised all sections. All authors have contributed to all sections of the paper and have edited it for intellectual content. NEF, CGM, DC, JRA, DPG, JMF, BWK, and PHF participated in the authors' meeting and discussion during the drafting process. All other authors have read and provided substantive intellectual comments on the draft and approved the final version of the paper.

The Lancet Low Back Pain Series Working Group

Steering Committee: Rachelle Buchbinder (Chair) Monash University, Melbourne, Australia; Jan Hartvigsen (Deputy Chair), University of Southern Denmark, Odense, Denmark; Dan Cherkin, Kaiser Permanente Washington Health Research Institute, Seattle, USA Nadine E Foster, Keele University, Keele, UK; Chris G Maher, University of Sydney, Sydney, Australia; Martin Underwood, Warwick University, Coventry, UK; Maurits van Tulder, Vrije Universiteit, Amsterdam, Netherlands.

Members: Johannes R Anema, VU University Medical Centre, Amsterdam, Netherlands; Roger Chou, Oregon Health and Science University, Portland, USA; Stephen P Cohen, Johns Hopkins School of Medicine, Baltimore, USA; Lucíola Menezes Costa, Universidade Cidade de Sao Paulo, Sao Paulo, Brazil; Peter Croft, Keele University, Keele, UK; Manuela Ferreira, Paulo H Ferreira, Damian Hoy, University of Sydney, Sydney, Australia; Julie M Fritz, University of Utah, Salt Lake City, USA; Stéphane Genevay, University Hospital of Geneva, Geneva, Switzerland; Douglas P Gross, University of Alberta, Edmonton, Canada;

Mark Hancock, Macquarie University, Sydney, Australia; Jaro Karppinen,
University of Oulu and Oulu University Hospital, Oulu, Finland; Bart W Koes, Erasmus MC, University Medical Center Rotterdam, Rotterdam, Netherlands; Alice Kongsted, University of Southern Denmark, Odense, Denmark; Quinette Louw, Stellenbosch University, Tygerberg, South Africa; Birgitta Öberg, Linkoping University, Linkoping, Sweden; Wilco Peul, Leiden University, Leiden, Netherlands; Glenn Pransky, University of Massachusetts Medical School, Worcester, USA Mark Schoene, The Back Letter, Lippincott Williams \& Wilkins, Newburyport, USA; Joachim Sieper, Charite, Berlin, Germany; Rob Smeets, Maastricht University, Maastricht, Netherlands; Judith A Turner, University of Washington School of Medicine, Seattle, USA; Anthony Woolf, Royal Cornwall Hospital and University of Exeter Medical School, Truro, UK.

\section{Declaration of interests}

Please see appendix for authors' declaration of interests.

\section{Acknowledgments}

There were no sources of funding for this paper. NEF is a UK National Institute for Health Research Senior Investigator, and was supported by a UK National Institute for Health Research Professorship (NIHR-RP-011-015). CGM is supported by Australian National Health and Medical Research Council Research Fellowships. JRA is supported through a Professorship in Insurance Medicine from the Dutch Social Security Agency. The conclusions in this Series paper are those of the authors and do not necessarily reflect the official position of any of the organisations, institutions, or agencies to which the authors are affiliated.

\section{References}

1 Freburger JK, Holmes GM, Agans RP, et al. The rising prevalence of chronic low back pain. Arch Intern Med 2009; 169: 251-58.

2 Hoy D, March L, Brooks P, et al. Measuring the global burden of low back pain. Best Pract Res Clin Rheumatol 2010; 24: 155-65.

3 Hartvigsen J, Hancock MJ, Kongsted A, et al. What low back pain is and why we need to pay attention. Lancet 2018; published online March 21. http://dx.doi.org/10.1016/S0140-6736(18)30480-X.

4 Steffens D, Maher CG, Pereira LS, et al. Prevention of low back pain: a systematic review and meta-analysis. JAMA Intern Med 2016; 176: 199-208.

5 Michaleff ZA, Kamper SJ, Maher CG, Evans R, Broderick C, Henschke N. Low back pain in children and adolescents: a systematic review and meta-analysis evaluating the effectiveness of conservative interventions. Eur Spine J 2014; 23: 2046-58.

6 Stochkendahl MJ, Kjaer P, Hartvigsen J, et al. National clinical guidelines for non-surgical treatment of patients with recent onset low back pain or lumbar radiculopathy. Eur Spine J 2018; 27: 60-75.

7 Qaseem A, Wilt TJ, McLean RM, Forciea MA, Clinical Guidelines Committee of the American College of Physicians. Noninvasive treatments for acute, subacute, and chronic low back pain: a clinical practice guideline from the American College of Physicians. Ann Intern Med 2017; 166: 514-30.

8 UK National Institute for Health and Care Excellence. Low back pain and sciatica in over 16s: assessment and management. November 2016. https://www.nice.org.uk/guidance/ng59 (accessed Nov 7, 2017).

9 Chou R, Deyo R, Friedly J, et al. Noninvasive treatments for low back pain: comparative effectiveness review No 169. Rockville, MD: Agency for Healthcare Research and Quality, 2016.

10 Wong JJ, Cote P, Sutton DA, et al. Clinical practice guidelines for the noninvasive management of low back pain: a systematic review by the Ontario Protocol for Traffic Injury Management (OPTIMA) Collaboration. Eur J Pain 2017; 21: 201-16.

11 Kamper SJ, Apeldoorn AT, Chiarotto A, et al. Multidisciplinary biopsychosocial rehabilitation for chronic low back pain Cochrane Database Syst Rev 2014; 9: CD000963.

12 Machado GC, Maher CG, Ferreira PH, et al. Efficacy and safety of paracetamol for spinal pain and osteoarthritis: systematic review and meta-analysis of randomised placebo controlled trials. BMJ 2015; 350: h1225.

13 Dowell D, Haegerich TM, Chou R. CDC guideline for prescribing opioids for chronic pain: United States, 2016. JAMA 2016; 315: 1624-45.

14 Mathieson S, Maher CG, McLachlan AJ, et al. Trial of pregabalin for acute and chronic sciatica. N Engl J Med 2017; 376: 1111-20. 
15 Chou R, Hashimoto R, Friedly J, et al. Epidural corticosteroid injections for radiculopathy and spinal stenosis: a systematic review and meta-analysis. Ann Intern Med 2015; 163: 373-81.

16 US Food and Drug Administration. Drug safety communication: FDA requires label changes to warn of rare but serious neurologic problems after epidural corticosteroid injections for pain. 2014. https://www.fda.gov/downloads/Drugs/DrugSafety/UCM394286.pdf (accessed Nov 7, 2017).

17 Juch JNS, Maas ET, Ostelo R, et al. Effect of radiofrequency denervation on pain intensity among patients with chronic low back pain: the Mint randomized clinical trials. JAMA 2017; 318: $68-81$.

18 Chou R, Baisden J, Carragee EJ, Resnick DK, Shaffer WO, Loeser JD. Surgery for low back pain: a review of the evidence for an American Pain Society clinical practice guideline. Spine 2009; 34: 1094-109.

19 Deyo RA, Mirza SK. Herniated lumbar intervertebral disk. N Engl J Med 2016; 374: 1763-72.

20 Weinstein JN, Tosteson TD, Lurie JD, et al. Surgical versus nonoperative treatment for lumbar spinal stenosis four-year results of the Spine Patient Outcomes Research Trial. Spine 2010; 35: 1329-38.

21 The Philippine Academy of Rehabilitation Medicine. Clinical practice guidelines on the diagnosis and management of low back pain. 2011. http://parm.com.ph/wp-content/uploads/2016/09/PARM-Low-BackPain-CPG-2011-1.pdf (accessed Nov 7, 2017).

22 Brazilian Association of Physical Medicine and Rehabilitation. Chronic nonspecific low back pain: Rehabilitation. Revista da Associação Médica Brasileira (English Edition) 2013; 59: 536-53.

23 Scott NA, Moga C, Harstall C. Managing low back pain in the primary care setting: the know-do gap. Pain Res Manag 2010; 15: 392-400.

24 Tcherny-Lessenot S, Karwowski-Soulie F, Lamarche-Vadel A, Ginsburg C, Brunet F, Vidal-Trecan G. Management and relief of pain in an emergency department from the adult patients' perspective. J Pain Symptom Manage 2003; 25: 539-46.

25 Eastwood K, Morgans A, Smith K, Hodgkinson A, Becker G, Stoelwinder J. A novel approach for managing the growing demand for ambulance services by low-acuity patients. Aust Health Rev 2016; 40: $378-84$.

26 Australian Institute of Health and Welfare. Back problems: musculoskeletal fact sheet. 2015. https://www.aihw.gov.au/ getmedia/72d28f53-cf36-40b9-b122-8415de81b1f7/back-problemsfactsheet-phe185.pdf.aspx?inline=true (accessed Nov 7, 2017).

27 Rosenberg A, Agiro A, Gottlieb M, et al. Early trends among seven recommendations from the choosing wisely campaign. JAMA Intern Med 2015; 175: 1913-20.

28 Bellan M, Molinari R, Castello L, et al. Profiling the patients visiting the emergency room for musculoskeletal complaints: characteristics and outcomes. Clin Rheumatol 2016; 35: 2835-39.

29 Mousavi SJ, Akbari ME, Mehdian H, et al. Low back pain in Iran: a growing need to adapt and implement evidence-based practice in developing countries. Spine 2011; 36: E638-46.

30 Yan LD, Mahadevan SV, Yore M, et al. An observational study of adults seeking emergency care in Cambodia. Bull World Health Organ 2015; 93: 84-92.

31 Fialho SC, de Castro GR, Zimmermann AF, et al. Musculoskeletal system assessment in an emergency room. Rev Bras Reumatol 2011; 51: $240-48$.

32 Goren A, Fujii R, Pandey A, Mould-Quevedo J. Prevalence of pain awareness, treatment, and associated health outcomes across different conditions in Brazil. Rev Dor Sao Paulo 2012; 13: 308-19.

33 Laffont M, Sequeira G, Kerzberg EM, Marconi E, Guevel C, de Las Mercedes Fernandez M. The non-silent epidemic: low back pain as a primary cause of hospitalisation. Rheumatol Int 2016; 36: 673-77.

34 Williams CM, Maher CG, Hancock MJ, et al. Low back pain and best practice care. A survey of general practice physicians. Arch Intern Med 2010; 70: 271-77.

35 Major-Helsloot ME, Crous LC, Grimmer-Somers K, Louw QA. Management of LBP at primary care level in South Africa: up to standards? Afr Health Sci 2014; 14: 698-706.

36 Buchbinder R, Staples M, Jolley D. Doctors with a special interest in back pain have poorer knowledge about how to treat back pain. Spine 2009; 34: 1218-26.
37 Bener A, Dafeeah EE, Alnaqbi K. Prevalence and correlates of low back pain in primary care: what are the contributing factors in a rapidly developing country. Asian Spine J 2014; 8: 227-36.

38 Fidvi N, May S. Physiotherapy management of low back pain in India: a survey of self-reported practice. Physiother Res Int 2010; 15: $150-59$

39 Pagare VK, Dhanraj T, Thakkar D, Sareen A, Palekar TJ. Beliefs about low back pain: Status quo in Indian general population. J Back Musculoskelet Rehabil 2015; 28: 731-37.

40 Margarido Mdo S, Kowalski SC, Natour J, Ferraz MB. Acute low back pain: diagnostic and therapeutic practices reported by Brazilian rheumatologists. Spine 2005; 30: 567-71.

41 Rizzardo A, Miceli L, Bednarova R, Guadagnin GM, Sbrojavacca R, Della Rocca G. Low-back pain at the emergency department: still not being managed? Ther Clin Risk Manag 2016; 12: $183-87$

42 Werner EL, Ihlebaek C. Primary care doctors' management of low back pain patients-ten years after. Tidsskr Nor Laegeforen 2012; 132: 2388-90.

43 Jenkins HJ. Awareness of radiographic guidelines for low back pain: a survey of Australian chiropractors. Chiropr Man Therap 2016; 24: 39.

44 Sahu R. Non-drug non-invasive treatment in the management of low back pain. Ann Med Health Sci Res 2014; 4: 780-85.

45 Yu L, Wang X, Lin X, Wang Y. The use of lumbar spine magnetic resonance imaging in eastern China: appropriateness and related factors. PLoS One 2016; 11: e0146369.

46 Jame SZ, Sari AA, Majdzadeh R, Rashidian A, Arab M, Rahmani H. The extent of inappropriate use of magnetic resonance imaging in low back pain and its contributory factors. Int J Prev Med 2014; 5: 1029-36.

47 Erdes Sh F, Dubinina TV, Galushko EA. Low back pain in general medical practice. Ter Arkh 2008; 80: 59-61.

48 Michaleff ZA, Harrison C, Britt H, Lin CW, Maher CG. Ten-year survey reveals differences in GP management of neck and back pain. Eur Spine J 2012; 21: 1283-89.

49 Bernhardsson S, Oberg B, Johansson K, Nilsen P, Larsson ME. Clinical practice in line with evidence? A survey among primary care physiotherapists in western Sweden. J Eval Clin Pract 2015; 21: 1169-77.

50 Madson TJ, Hollman JH. Lumbar traction for managing low back pain: a survey of physical therapists in the United States. J Orthop Sports Phys Ther 2015; 45: 586-95.

51 Keating JL, McKenzie JE, O'Connor DA, et al. Providing services for acute low-back pain: a survey of Australian physiotherapists. Man Ther 2016; 22: 145-52.

52 Serrano-Aguilar P, Kovacs FM, Cabrera-Hernandez JM, Ramos-Goni JM, Garcia-Perez L. Avoidable costs of physical treatments for chronic back, neck and shoulder pain within the Spanish National Health Service: a cross-sectional study. BMC Musculoskelet Disord 2011; 12: 287.

53 Pensri P, Foster NE, Srisuk S, Baxter GD, McDonough SM. Physiotherapy management of low back pain in Thailand: a study of practice. Physiother Res Int 2005; 10: 201-12.

54 Oppong-Yeboah B, May S. Management of low back pain in Ghana: a survey of self-reported practice. Physiother Res Int 2014; 19: 222-30.

55 Jeffrey Kao MC, Minh LC, Huang GY, Mitra R, Smuck M. Trends in ambulatory physician opioid prescription in the United States, 1997-2009. PM R 2014; 6: 575-82.

56 Carey TS, Freburger JK, Holmes GM, et al. A long way to go: practice patterns and evidence in chronic low back pain care. Spine 2009; 34: 718-24.

57 Deyo RA, Smith DH, Johnson ES, et al. Opioids for back pain patients: primary care prescribing patterns and use of services. J Am Board Fam Med 2011; 24: 717-27.

58 Pain \& Policy Studies Group. Custom consumption graphs for opioid medicines. https://ppsg-chart.medicine.wisc.edu./ (accessed Nov 8, 2017).

59 Weiss AJ, Elixhauser A, Andrews RM. Characteristics of operating room procedures in U.S. hospitals, 2011. The Healthcare Cost and Utilization Project Statistical Brief 170. 2014. https://hcup-us.ahrq. gov/reports/statbriefs/sb170-Operating-Room-Procedures-UnitedStates-2011.jsp (accessed Nov 7, 2017). 
60 Manchikanti L, Pampati V, Singh V, Falco FJ. Assessment of the escalating growth of facet joint interventions in the medicare population in the United States from 2000 to 2011. Pain Physician 2013; 16: E365-78.

61 Manchikanti L, Hansen H, Pampati V, Falco FJ. Utilization and growth patterns of sacroiliac joint injections from 2000 to 2011 in the medicare population. Pain Physician 2013; 16: E379-90.

62 Willems P, de Bie R, Oner C, Castelein R, de Kleuver M. Clinical decision making in spinal fusion for chronic low back pain. Results of a nationwide survey among spine surgeons. BMJ Open 2011; 1: e000391.

63 Machado GC, Maher CG, Ferreira PH, et al. Trends, complications, and costs for hospital admission and surgery for lumbar spinal stenosis. Spine 2017; 42: 1737-43.

64 Manchikanti L, Pampati V, Falco FJ, Hirsch JA. Assessment of the growth of epidural injections in the medicare population from 2000 to 2011. Pain Physician 2013; 16: E349-64.

65 Teles AR, Righesso O, Gullo MC, Ghogawala Z, Falavigna A. Perspective of value-based management of spinal disorders in Brazil. World Neurosurg 2016; 87: 346-54.

66 Saragiotto BT, Maher CG, Yamato TP, Costa LOP, Ostelo RWJG, Macedo LG. Motor control exercise for chronic non-specific low back pain. Cochrane Database Syst Rev 2016; 1: CD012004.

67 Australian Government Department of Health. Chronic disease management - provider information: fact sheet. 2016 http://www.health.gov.au/internet/main/publishing.nsf/Content/ mbsprimarycare-factsheet-chronicdisease.htm (accessed Mar 27, 2018).

68 Bello AI, Quartey J, Lartey M. Efficacy of behavioural graded activity compared with conventional exercise therapy in chronic non-specific low back pain: implication for direct health care cost. Ghana Med J 2015; 49: 173-80.

69 Ivanova JI, Birnbaum HG, Schiller M, Kantor E, Johnstone BM, Swindle RW. Real-world practice patterns, health-care utilization, and costs in patients with low back pain: the long road to guideline-concordant care. Spine J 2011; 11: 622-32.

70 Nunn ML, Hayden JA, Magee K. Current management practices for patients presenting with low back pain to a large emergency department in Canada. BMX Musculoskeletal Disorders 2017; 18: 92.

71 Friedman BW, Chilstrom M, Bijur PE, Gallagher EJ. Diagnostic testing and treatment of low back pain in United States emergency departments: a national perspective. Spine 2010; 35: E1406-11.

72 Deyo RA, Von Korff M, Duhrkoop D. Opioids for low back pain. BMJ 2015; 350: g6380.

73 Abdel Shaheed C, Maher CG, Williams KA, Day R, McLachlan AJ. Efficacy, tolerability, and dose-dependent effects of opioid analgesics for low back pain: a systematic review and meta-analysis. JAMA Intern Med 2016; 176: 958-68.

74 Chaparro LE, Furlan AD, Deshpande A, Mailis-Gagnon A, Atlas S, Turk DC. Opioids compared with placebo or other treatments for chronic low back pain: an update of the Cochrane Review. Spine 2014; 39: 556-63.

75 Chou R, Deyo RA, Jarvik JG. Appropriate use of lumbar imaging for evaluation of low back pain. Radiol Clin North Am 2012; 50: 569-85.

76 Guy GP Jr, Zhang K, Bohm MK, et al. Vital signs: changes in opioid prescribing in the United States, 2006-2015 MMWR Morb Mortal Wkly Rep 2017; 66: 697-704.

77 Deyo RA, Mirza SK, Martin BI, Kreuter W, Goodman DC, Jarvik JG. Trends, major medical complications, and charges associated with surgery for lumbar spinal stenosis in older adults. JAMA 2010; 303: 1259-65.

78 Forsth P, Olafsson G, Carlsson T, et al. A randomized, controlled trial of fusion surgery for lumbar spinal stenosis. N Engl J Med 2016; 374: 1413-23.

79 Sharp AL, Chang T, Cobb E, et al. Exploring real-time patient decision-making for acute care: a pilot study. West J Emerg Med 2014; 15: 675-81

80 Edwards J, Hayden J, Asbridge M, Gregoire B, Magee K. Prevalence of low back pain in emergency settings: a systematic review and meta-analysis. BMC Musculoskelet Disord 2017; 18: 143.

81 Ehde DM, Dillworth TM, Turner JA. Cognitive-behavioral therapy for individuals with chronic pain: efficacy, innovations, and directions for research. Am Psychol 2014; 69: 153-66.
82 Baker SR, Rabin A, Lantos G, Gallagher EJ. The effect of restricting the indications for lumbosacral spine radiography in patients with acute back symptoms. AJR Am J Roentgenol 1987; 149: 535-8.

83 Eccles M, Steen N, Grimshaw J, et al. Effect of audit and feedback, and reminder messages on primary-care radiology referrals: a randomised trial. Lancet 2001; 357: 1406-9.

84 Riis A, Jensen CE, Bro F, et al. A multifaceted implementation strategy versus passive implementation of low back pain guidelines in general practice: a cluster randomised controlled trial. Implement Sci 2016; 11: 143.

85 Jensen CE, Riis A, Petersen KD, Jensen MB, Pedersen KM. Economic evaluation of an implementation strategy for the management of low back pain in general practice. Pain 2017; 158: 891-99.

86 Hill JC, Dunn KM, Lewis M, et al. A primary care back pain screening tool: identifying patient subgroups for initial treatment. Arthritis Rheum 2008; 59: 632-41.

87 Hill JC, Whitehurst DG, Lewis M, et al. Comparison of stratified primary care management for low back pain with current best practice (STarT Back): a randomised controlled trial. Lancet 2011; 378: 1560-71.

88 Foster NE, Mullis R, Hill JC, et al. Effect of stratified care for low back pain in family practice (IMPaCT Back): a prospective population-based sequential comparison. Ann Fam Med 2014 12: $102-11$.

89 Fourney DR, Dettori JR, Hall H, Hartl R, McGirt MJ, Daubs MD A systematic review of clinical pathways for lower back pain and introduction of the Saskatchewan Spine Pathway. Spine 2011; 36 (suppl): S164-71.

90 Kindrachuk DR, Fourney DR. Spine surgery referrals redirected through a multidisciplinary care pathway: effects of nonsurgeon triage including MRI utilization. J Neurosurg Spine 2014; 20: 87-92.

91 Wilgenbusch CS, Wu AS, Fourney DR. Triage of spine surgery referrals through a multidisciplinary care pathway: a value-based comparison with conventional referral processes. Spine 2014; 39 (suppl 1): S129-35.

92 Greenough CG for the Clinical Group. NHS England national pathfinder projects: trauma programme of care pathfinder project-low back pain and radicular pain: report of the clinical group: national pathway of care for low back and radicular pain. Dec 17, 2014. http://rcc-uk.org/wp-content/uploads/2015/01/ Pathfinder-Low-back-and-Radicular-Pain.pdf (accessed Nov 8, 2017).

93 Lingard L. Independent evaluation of implementation of acute low back and radicular pain pathway in South Tees CCG and Hambleton, Richmondshire and Whitby CCG. North East Quality Observatory Service. August, 2016. http://www.ahsn-nenc.org.uk/ wp-content/uploads/2014/12/NEQOS-Independent-Evaluation-of AHSN-Back-Pain-Pathway-Project-1.08.2016.pdf (accessed Nov 8, 2017).

94 UK Spine Societies Board. Improving spinal care project. 2017: https://www.ukssb.com/improving-spinal-care-project (accessed Feb 14, 2018).

95 Wickizer TM, Franklin G, Fulton-Kehoe D, et al. Improving quality, preventing disability and reducing costs in workers' compensation healthcare: a population-based intervention study. Med Care 2011; 49: $1105-11$.

96 Linton SJ, Boersma K, Traczyk M, Shaw W, Nicholas M. Early workplace communication and problem solving to prevent back disability: results of a randomized controlled trial among high-risk workers and their supervisors. J Occup Rehabil 2016; 26: 150-59.

97 Lambeek LC, van Mechelen W, Knol DL, Loisel P, Anema JR. Randomised controlled trial of integrated care to reduce disability from chronic low back pain in working and private life. BMJ 2010; 340: $\mathrm{c} 1035$.

98 Lambeek LC, Bosmans JE, Van Royen BJ, Van Tulder MW, Van Mechelen W, Anema JR. Effect of integrated care for sick listed patients with chronic low back pain: economic evaluation alongside a randomised controlled trial. BMJ 2010; 341: c6414.

99 Anema J, Prinz C, Prins R. Sickness and disability policy interventions. In: Loisel P, Anema J, eds. Handbook of work disability: prevention and management. New York, NY: Springer, 2013: 357-71. 
100 Lambeek LC, van Tulder MW, Swinkels IC, Koppes LL, Anema JR, van Mechelen W. The trend in total cost of back pain in the Netherlands in the period 2002 to 2007. Spine 2011; 36: 1050-58.

101 Buchbinder R, Jolley D, Wyatt M. Population based intervention to change back pain beliefs and disability: three part evaluation. BMJ 2001; 322: 1516-20.

102 Buchbinder R, Gross DP, Werner EL, Hayden JA. Understanding the characteristics of effective mass media campaigns for back pain and methodological challenges in evaluating their effects. Spine 2008; 33: 74-80.

103 Buchbinder R, Jolley D, Wyatt M. 2001 Volvo award winner in clinical studies: effects of a media campaign on back pain beliefs and its potential influence on management of low back pain in general practice. Spine 2001; 26: 2535-42.

104 Gross DP, Russell AS, Ferrari R, et al. Evaluation of a Canadian back pain mass media campaign. Spine 2010; 35: 906-13.

105 Suman A, Bostick G, Schopflocher D, et al. Long-term evaluation of a Canadian back pain mass media campaign. Eur Spine J 2017; published online Aug 3. DOI:10.1007/s00586-017-5249-6.

106 Baker R, Camosso-Stefinovic J, Gillies C, et al. Tailored interventions to overcome identified barriers to change: effects on professional practice and health care outcomes. Cochrane Database Syst Rev 2010; 3: CD005470.

107 Fischer F, Lange K, Klose K, Greiner W, Kraemer A. Barriers and strategies in guideline implementation: a scoping review. Healthcare (Basel) 2016; 4: E36.

108 Slade SC, Kent P, Patel S, Bucknall T, Buchbinder R. Barriers to primary care clinician adherence to clinical guidelines for the management of low back pain: a systematic review and meta-synthesis of qualitative studies. Clin J Pain 2015; 32: 800-16.

109 Suman A, Dikkers MF, Schaafsma FG, van Tulder MW, Anema JR. Effectiveness of multifaceted implementation strategies for the implementation of back and neck pain guidelines in health care: a systematic review. Implement Sci 2016; 11: 126.

110 Mesner SA, Foster NE, French SD. Implementation interventions to improve the management of non-specific low back pain: a systematic review. BMC Musculoskelet Disord 2016; 17: 258.

111 Jensen C, Jensen M, Riis A, Petersen K. Systematic review of the cost-effectiveness of implementing guidelines on low back pain management in primary care: is transferability to other countries possible? BMJ Open 2016; 6: e011042.

112 Myburgh C, Mouton J. The development of contemporary chiropractic education in Denmark: an exploratory study. J Manipulative Physiol Ther 2008; 31: 583-92.

113 Foster NE, Hartvigsen J, Croft PR. Taking responsibility for the early assessment and treatment of patients with musculoskeletal pain: a review and critical analysis. Arthritis Res Ther 2012; 14: 205

114 Weiner DK, Morone NE, Spallek H, et al. E-learning module on chronic low back pain in older adults: evidence of effect on medical student objective structured clinical examination performance. J Am Geriatr Soc 2014; 62: 1161-67.

115 Overmeer T, Boersma K, Main CJ, Linton SJ. Do physical therapists change their beliefs, attitudes, knowledge, skills and behaviour after a biopsychosocially orientated university course? J Eval Clin Pract 2009; 15: 724-32.

116 Vanhaecht K, Sermeus W, Peers J, et al. The European Quality of Care Pathway (EQCP) study: history, project management and approach. Int J Care Coord 2010; 14: 52-56.

117 Panella M, Marchisio S, Di Stanislao F. Reducing clinical variations with clinical pathways: do pathways work? Int J Qual Health Car 2003; 15: 509-21.

118 Fuhrmans V. Withdrawal treatment: a novel plan helps hospital wean itself off pricey tests. The Wall Street Journal (New York). Jan 12, 2007.

119 Steenstra I, Busse J, Hogg-Johnson S. Predicting return to work for workers with low back pain. In: Loisel P, Anema J, eds. Work disability prevention handbook. New York, NY: Springer, 2013: 255-66.

120 Steenstra IA, Munhall C, Irvin E, et al. Systematic review of prognostic factors for return to work in workers with sub-acute and chronic low back pain. J Occup Rehabil 2017; 27: 369-81.
121 Henschke N, Maher CG, Refshauge KM, et al. Prognosis in patients with recent onset low back pain in Australian primary care: inception cohort study. BMJ 2008; 337: a171.

122 South African Department of Health. Framework and strategy for disability and rehabilitation services in South Africa (2015-2020). 2015. http://ilifalabantwana.co.za/wp-content/uploads/2016/07/ Framework-25-may_1_3.docx (accessed Nov 8, 2017).

123 Vermeulen SJ, Anema JR, Schellart AJ, Knol DL, van Mechelen W, van der Beek AJ. A participatory return-to-work intervention for temporary agency workers and unemployed workers sick-listed due to musculoskeletal disorders: results of a randomized controlled trial. J Occup Rehabil 2011; 21: 313-24.

124 Suman A, Bostick GP, Schaafsma FG, Anema JR, Gross DP. Associations between measures of socio-economic status, beliefs about back pain, and exposure to a mass media campaign to improve back beliefs. BMC Public Health 2017; 17: 504.

125 Volinn E, Nishikitani M, Volinn W, Nakamura Y, Yano E. Back pain claim rates in Japan and the United States: framing the puzzle. Spine 2005; 30: 697-704.

126 Vieira ER, Albuquerque-Oliveira PR, Barbosa-Branco A. Work disability benefits due to musculoskeletal disorders among Brazilian private sector workers. BMJ Open 2011; 1: e000003.

127 Cassidy JD, Carroll L, Cote P, Berglund A, Nygren A. Low back pain after traffic collisions: a population-based cohort study. Spine 2003; 28: 1002-09.

128 Elbers NA, Collie A, Hogg-Johnson S, Lippel K, Lockwood K, Cameron ID. Differences in perceived fairness and health outcomes in two injury compensation systems: a comparative study. BMC Public Health 2016; 16: 658.

129 Souza NS, Santana VS. Factors associated with duration of disability benefits: a cohort study. Rev Saude Publica 2012; 46: 425-34.

130 Organisation for Economic Co-operation and Development. Transforming disability into ability: polices to promote work and income security for disabled people. 2003. http://www.oecd.org/els/ emp/transformingdisabilityintoability.htm (accessed Nov 8, 2017).

131 Organisation for Economic Co-operation and Development. Sickness, disability and work: breaking the barriers: a synthesis of findings across OECD countries. Nov 24, 2010. http://www.oecd. org/publications/sickness-disability-and-work-breaking-the-barriers9789264088856-en.htm (accessed Nov 8, 2017).

132 Collie A, Lane TJ, Hassani-Mahmooei B, Thompson J, McLeod C. Does time off work after injury vary by jurisdiction? A comparative study of eight Australian workers' compensation systems. BMJ Open 2016; 6: e010910.

133 Anema JR, Schellart AJ, Cassidy JD, Loisel P, Veerman TJ, van der Beek AJ. Can cross country differences in return-to-work after chronic occupational back pain be explained? An exploratory analysis on disability policies in a six country cohort study. J Occup Rehabil 2009; 19: 419-26.

134 Bartys S, Frederiksen P, Bendix T, Burton K. System influences on work disability due to low back pain: An international evidence synthesis. Health Policy 2017; 121: 903-12.

135 Waddell G, O'Connor M, Boorman S, Torsney B. Working Backs Scotland: a public and professional health education campaign for back pain. Spine 2007; 32: 2139-43.

136 Werner EL, Ihlebaek C, Laerum E, Wormgoor ME, Indahl A. Low back pain media campaign: no effect on sickness behaviour. Patient Educ Couns 2008; 71: 198-203.

137 Hoy D, Geere JA, Davatchi F, Meggitt B, Barrero LH. A time for action: Opportunities for preventing the growing burden and disability from musculoskeletal conditions in low- and middle-income countries. Best Pract Res Clin Rheumatol 2014; 28: 377-93.

138 Hoy D, Beyer H, Morgan C, Toole M. The back happy tap-stand. $J$ Water Supply Res T 2005; 54: 261-63.

139 South African Western Cape Government. Wow! (Western Cape on Wellness) Healthy Lifestly Initiative. https://www.westerncape.gov. za/westerncape-on-wellness/about-us (accessed Nov 8, 2017).

(C) 2018 Elsevier Ltd. All rights reserved. 